\title{
Productive and environmental performance indicators analysis by a combined LCA hybrid model and real-time manufacturing process monitoring: A grinding unit process application
}

\author{
Remo Augusto Padovezi Filleti a, *, Diogo Aparecido Lopes Silva ${ }^{\text {, }}$, \\ Eraldo Jannone da Silva ${ }^{c}$, Aldo Roberto Ometto ${ }^{c}$ \\ ${ }^{a}$ PhD Program in Science and Management of Climate Change, Department of Economics, Ca'Foscari University of Venice, Cannaregio 873, Venice, 30123, \\ Italy \\ b Department of Production Engineering, Center of Sciences and Technologies for Sustainability, Federal University of São Carlos, João Leme dos Santos Road \\ (SP-264), Km 110, Itinga District, Sorocaba, 18052-780, Brazil \\ ${ }^{\mathrm{c}}$ Department of Production Engineering, School of Engineering of São Carlos, University of São Paulo, 400 Trabalhador São Carlense Avenue, São Carlos, \\ 13566-590, Brazil
}

\section{A R T I C L E I N F O}

\section{Article history:}

Received 11 November 2016

Received in revised form

8 May 2017

Accepted 25 May 2017

Available online 26 May 2017

Handling Editor: Yutao Wang

\section{Keywords:}

Abrasive process

Grinding

Life cycle inventory

Life cycle inventory assessment

Cubic boron nitride

\begin{abstract}
A B S T R A C T
Among machining processes, grinding has been used to achieve high dimensional tolerances and surface quality on workpieces. Yet, high levels of energy expenditure per volume of removed material and the need for cutting fluids make grinding one of the most environmentally impactful machining processes. Furthermore, changes in parameters such as grain and bond specifications of the grinding wheel, cutting speed, and specific material removal rate can lead to different productive and environmental results. Thus, the analysis of grinding processes should not be aggregated and leveraged into a single and broad output parameter. Instead, comprehensive study should be performed, in which the most relevant process parameters, inputs and outputs are considered. This paper presents a detailed study of grinding process, including the characterization of machine subunits and production modes, along with the use of a combined life cycle assessment hybrid model and real-time monitoring system to evaluate the consumption of energy, tooling, cutting fluid and compressed air. A detailed cradle-to-gate life cycle assessment study using eleven different impact categories and a productive performance assessment were performed to evaluate the effects on varying specific material removal rate and wheel type. For equal values of specific material removal rate, the change from a conventional wheel to a cubic boron nitride represented a power requirement increase of $19-24 \%$. Cubic boron nitride wheel achieved remarkably better results on the wheel wear and part roughness indicators for all tested conditions. The environmental performance assessment showed a strict relation between the process environmental impacts and the consumption of electric energy and cutting fluid. To conclude, despite the higher power requirements, the combination of cubic boron nitride wheel with high values of specific material removal rate optimizes both the productive and the environmental results.
\end{abstract}

() 2017 Elsevier Ltd. All rights reserved.

\section{Introduction}

Grinding is traditionally designated as a final machining process, providing superior surface properties to the ground part, such as smoother surfaces and tighter dimensional tolerances (Malkin and Guo, 2008; Winter et al., 2015). These improved surface

\footnotetext{
* Corresponding author

E-mail address: remo.filleti@gmail.com (R.A.P. Filleti).
}

properties can positively affect the part lifespan and function efficiency (e.g., by friction reduction of the ground part), thereby reducing the negative potential environmental impacts during its usage (Aurich et al., 2013; Kirsch et al., 2014; Linke and Overcash, 2012).

Aspects such as grain and bond specifications of the grinding wheel, dressing conditions and type of cutting fluid can lead to different levels of environmental and productive performances, and poses a real challenge to the sustainable manufacturing of products. Aurich et al. (2013) noticed that the variation of process 
parameters in different grinding machines could lead to very different overall energy consumptions, even when the same material (DIN 42CrMo4V/hardness $60 \mathrm{HRc}$ ) is machined. Based upon this premise, grinding processes cannot be aggregated and leveraged into a single and broad output parameter. Instead, it is necessary to promote a comprehensive study in which the most relevant inputs and outputs are considered. To this end, Life Cycle Assessment (LCA) technique appears as an option to evaluate the potential environmental impacts of manufacturing process.

Life Cycle Assessment (LCA) is a well-established methodology to assess environmental impacts of products and processes (ISO, 2006a, 2006b; Joint Research Centre - JRC, 2010). However, issues involving data quality and data collection during the Life Cycle Inventory ( $\mathrm{LCI}$ ) stage are some of the main constraints from this methodology.

Among the LCA's phases, LCI demands more efforts, time and resources to be properly performed (Bourhis et al., 2013; Thorn et al., 2011). Skone and Curran (2005) report that LCA has undergone consistent improvements in terms of its methodology structure and standardization, but little has been done to improve the availability of high quality LCI databases.

Most of the available LCI databases have been developed by governmental or private initiatives, usually based on regional or aggregated average data (Thorn et al., 2011). It is also common to find LCI databases adopting "black-box" datasets, regarding the manufacturing processes (Silva et al., 2016).

Thorn et al. (2011) and Vijayaraghavan et al. (2013) argue that high quality LCI data requires site-specific and sensor-based monitoring systems, with a software interface which allows the real-time measurement of the process flows and parameters. In fact, market available systems, such as Energy Management System (EMS) and Object linking and embedding for Process Control (OPC) already perform dynamic monitoring in machining unit processes, including grinding machines. However, the first one is limited only to energy monitoring while none of them include web-based interfaces (Shao et al., 2011; Torrisi and Oliveira, 2012).

In this sense, some OPC-based protocols, such as OPC-UA, OPC$\mathrm{XML}$ and CyberOPC, appear as web communication solutions. By means of an OPC server, these protocols provide the basis for the standardization of the data collected from the unit process and allow its remote access and transfer by internet (Torrisi and Oliveira, 2012).

Vijayaraghavan et al. (2008) also presented a solution named MTConnect. This solution is a web-based open-source protocol, which defines a common language for communication and data sharing among manufacturing processes and their associated embedded devices, using market-based languages such as XML and HTML.

This protocol is extensible and does not compete with other existing protocols or applications, but it strives to complement them and move toward a plug-and-play environment to enhance data acquisition capability and to reduce costs of integration.

Moreover, gathering data in XML format allows the creation of LCI datasets based on other available standards, such as ecoSpold and International reference Life Cycle Data system (ILCD) formats, and facilitates the integration of manufacturing datasets with LCA software tools (Filleti et al., 2014).

The objective of this paper is to develop a combined LCA hybrid model and real-time manufacturing process monitoring to perform a detailed cradle-to-gate life cycle assessment study and a productive performance assessment study. The model is based on the Unit Process Life Cycle Inventory (UPLCI) methodology (Kellens et al., 2012a, 2012b) and on the MTConnect communication protocol.

The key aspects for environmental and productive assessment of grinding processes are presented in Section 2. Section 3 presents the experimental procedure used on the study. The results regarding the process consumption, productive performance and environmental performance are presented in Section 4. Finally, conclusions and outlooks of this study are discussed in Section 5.

\section{Key aspects for environmental and productive assessment of grinding process}

Sustainable aspects of grinding have attracted increasingly attention from both industry and academia (Linke and Overcash, 2012). High specific energy rates (Aurich et al., 2013; Winter et al., 2015) and use of environmentally harmful cutting fluids (Chetan et al., 2015; Clarens et al., 2008; Hadad, 2015) are some examples.

Nevertheless, just the analysis and improvement of its environmental performance may not guarantee an enhancement of the process sustainability. Aurich et al. (2013) pointed out that abrasive manufacturing processes such as grinding are tightly linked to the surface quality and integrity of the machined part. Thus, a sustainable analysis of this type of process must consider both the environmental and productive performance indicators.

Aurich et al. (2013) evaluated 13 different grinding setups in terms of specific energy consumption and surface arithmetic average roughness $\left(R_{a}\right)$. The setups were obtained by varying the type of grinding process, wheel abrasives, wheel grit sizes, cutting fluids, cutting speed and $\mathrm{Q}^{\prime}{ }_{\mathrm{w}}$. For all setups, DIN $42 \mathrm{CrMo} 4 \mathrm{~V}$ (hardness $60 \mathrm{HRc}$ ) workpieces were used.

The results showed that variations in $Q^{\prime}{ }_{w}$ and wheel grain grit parameters considerable interfere on the results of specific energy consumption and surface arithmetic average roughness $\left(R_{a}\right)$. In addition, the composition of the cutting fluids has a strong influence on the workpiece surface finishing, tool wear and the environmental impact results (Aurich et al., 2013; Clarens et al., 2008). Thus, the use of average and aggregated LCI data to evaluate grinding environmental and productive performances should be avoided. High quality and stratified data is required to proper assess the trade-offs resulting from productive and environmental performances of manufacturing processes.

Linke and Overcash (2012) developed an UPLCI-based framework to address productive, environmental and social factors of grinding, considering the process inputs (e.g., electric energy, cutting fluid, tooling), outputs (e.g., debris, dirty cutting fluid) and parameters (e.g., $\mathrm{Q}^{\prime}{ }_{\mathrm{w}}$ ). This study, however, remained at a theoretical level.

Li et al. (2012) addressed the eco-efficiency of grinding process using an empirical model, which characterize the interrelationship among process parameters (e.g., $\mathrm{Q}^{\prime}{ }_{\mathrm{w}}$ ), energy and tooling consumption, environmental impacts (i.e., carbon footprint) and quality performance. Winter et al. (2014) enhanced this analysis by adding the economic costs and the global warming potential impacts related to the use of cutting fluids in the evaluation. In a study regarding the LCA of cBN grinding wheels, Winter et al. (2015) expanded the environmental analysis and made use of an aggregated indicator, Eco-Indicator'99, to address other impact categories other than carbon footprint. Still, these approaches may be expanded and address a broader range of impact categories and in a non-aggregated way.

\section{Experimental procedure}

The case study was conducted in an external cylindrical grinding CNC machine (model Numerika G 800-HS, from Zema Zselics Ltd.) fed-in by a $220 \mathrm{~V}$ three-phase power supply and a 7-bar compressed air supply, sited at the Laboratory for Advanced Processes 
and Sustainability (LAPRAS), University of São Paulo (USP), Brazil.

Both productive and environmental analyses were performed by testing two types of grinding wheel - a conventional $\mathrm{Al}_{2} \mathrm{O}_{3}$ wheel (55A46-1-K8VC1 specification, vitrified bond and external diameter $\mathrm{d}_{\mathrm{s}}=475 \mathrm{~mm}$ ) and a cBN wheel (8B126 K150 VT2 specification, vitrified bond and $d_{s}=400 \mathrm{~mm}$ ). For each wheel, three different plunge grinding conditions were defined, leading to a total of six experiments. Two replications were performed for each condition.

For all experiments, workpiece rotation $\left(\mathrm{n}_{\mathrm{w}}\right)$ and grinding width $\left(b_{\mathrm{w}}\right)$ were fixed in $200 \mathrm{rpm}$ and $15 \mathrm{~mm}$, respectively. The application of cutting fluid at the grinding zone was adjusted for $50,000 \mathrm{~cm}^{3} / \mathrm{min}$ for all tests. Cutting speeds $\left(\mathrm{v}_{\mathrm{s}}\right)$ of 80 and $45 \mathrm{~m} / \mathrm{s}$ were selected, respectively, for the $\mathrm{cBN}$ and $\mathrm{Al}_{2} \mathrm{O}_{3}$ wheels. A sparkout time of $10 \mathrm{~s}$ was used for all grinding conditions.

The specific material removal rates were defined based on the regular working range from each wheel and on previous tests. Table 1 presents the summary of all the tested conditions:

Previous tests showed that $\mathrm{Q}^{\prime}{ }_{\mathrm{w}}=2.5 \mathrm{~mm} / \mathrm{mm} \cdot \mathrm{s}$ was not suitable for $\mathrm{Al}_{2} \mathrm{O}_{3}$ wheel as it quickly wore out under low volumes of material removal. In the opposite direction, previous tests indicated that $\mathrm{Q}^{\prime}{ }_{\mathrm{w}}=0.167 \mathrm{~mm}^{3} / \mathrm{mm} \cdot \mathrm{s}$ was an underload condition for the cBN wheel, so it was not addressed for this wheel.

Table 2 shows the dressing conditions for each wheel. Due its superabrasive nature, the $\mathrm{cBN}$ wheel was dressed using an electric rotary dressing system with an electro-plated diamond dressing disc. The conventional $\mathrm{Al}_{2} \mathrm{O}_{3}$ wheel, on the other hand, was dressed using a regular and static Fliesen dressing tool.

A characterization of the grinding unit process was performed by means of a LCI study. Among the different LCI approaches used for the evaluation of manufacturing process, e.g., exergy analysis (Gutowski et al., 2006), theoretical and statistical formulas (Abele et al., 2005) and process simulation (Bourhis et al., 2013), the Unit Process Life Cycle Inventory (UPLCI) methodology (Kellens et al., 2012a, b) was selected for this study.

The UPLCI presents a well-defined structure, which allows the collection of stratified data per subunit level (e.g., hydraulic subunit, cooling subunit) and production modes (e.g., start-up mode, stand-by mode, OFF mode) of machines, creating detailed unit process inventories.

Table 1

Tested grinding conditions.

\begin{tabular}{|c|c|c|c|c|c|}
\hline Test code & $\begin{array}{l}\mathrm{Q}^{\prime}{ }_{\mathrm{w}} \\
{\left[\mathrm{mm}^{3} / \mathrm{mm} \cdot \mathrm{s}\right]}\end{array}$ & $\begin{array}{l}\mathrm{v}_{\mathrm{s}} \\
{[\mathrm{m} / \mathrm{s}]}\end{array}$ & $\begin{array}{l}\mathrm{d}_{\mathrm{s}} \\
{[\mathrm{mm}]}\end{array}$ & $\begin{array}{l}\mathrm{n}_{\mathrm{w}} \\
{[\mathrm{rpm}]}\end{array}$ & $\begin{array}{l}\mathrm{b}_{\mathrm{w}} \\
{[\mathrm{mm}]}\end{array}$ \\
\hline cBN_Q ${ }^{\prime}{ }_{w} 0.83$ & 0.83 & 80 & 400 & 200 & 15 \\
\hline cBN_Q ${ }_{w}^{\prime} 1.67$ & 1.67 & 80 & 400 & 200 & 15 \\
\hline cBN_Q ${ }^{\prime}{ }_{w} 2.5$ & 2.50 & 80 & 400 & 200 & 15 \\
\hline $\mathrm{Al}_{2} \mathrm{O}_{3}{ }_{-} \mathrm{Q}_{\mathrm{w}}^{\prime} 0.167$ & 0.167 & 45 & 475 & 200 & 15 \\
\hline $\mathrm{Al}_{2} \mathrm{O}_{3} \mathrm{Q}^{\prime}{ }_{\mathrm{w}} 0.83$ & 0.83 & 45 & 475 & 200 & 15 \\
\hline $\mathrm{Al}_{2} \mathrm{O}_{3} \mathrm{Q}^{\prime}{ }_{\mathrm{w}} 1.67$ & 1.67 & 45 & 475 & 200 & 15 \\
\hline
\end{tabular}

\subsection{Functional unit and system boundary}

The functional unit was defined as $3000 \mathrm{~mm}^{3}$ material removal from a cylindrical workpiece by grinding and with no intermediary wheel dressing. The workpiece is made with nickel-chrome Inconel 751 alloy, has $150 \mathrm{~mm}$ of length, $28.30 \mathrm{~mm}$ of external diameter $\left(\mathrm{d}_{\mathrm{w}}\right)$ and was previously machined in a turning operation.

Additionally, the surface of the ground workpiece shall present a $R_{a}$ value lower than $1 \mu \mathrm{m}$ as a productive performance parameter. This $R_{a}$ threshold is in accordance with finishing performance expected from grinding process (Diniz et al., 2013).

The reference flow used in this study was $3000 \mathrm{~mm}^{3}$ material removal per grinding test (i.e., a complete machining of one workpiece). The UPLCI methodology suggests the use of $1 \mathrm{~s}$ of processing time as reference flow (Kellens et al., 2012a), however, this may not be the best choice in this case. According to Silva et al. (2015), the use of volume of material removed as reference flow enables a better evaluation of how the variation of grinding parameters can impact the environmental performance indicators in an LCA study of manufacturing processes, in comparison to the use of $1 \mathrm{~s}$ of processing time.

The definition of the system boundary has followed the directives from the UPLCI methodology and considered the inputs and outputs flows associated solely with the unit process operation, as reported by Fig. 1. In addition, the inventory data related to the product itself (i.e., the workpiece) and its upstream and downstream life cycle phases were not included into this study.

\subsection{Machine subunits}

Based on the system boundary definition (Fig. 1) and after a detailed study of the grinding machine operation, nine different subunits were identified (Fig. 2):

- Primary subunit (Prim): this subunit oversees supporting operations such as illumination, monitoring, machine controlling and interface. It consists of the machine illumination system, PC, $\mathrm{CNC}$, measurement instruments and sensors;

- Hydraulic subunit (Hydr): this subunit is in charge to supply the pressurized oil demand for the rotating bearings, the hydrostatic rails and the tailstock. It consists of vane pump, reservoir, servo-driven valves and filter;

- Cooling subunit (Cool): this subunit is responsible for the temperature control of both hydraulic and cutting fluids. It consists of a cold-water compartment (8000 kcal/h capacity) and three heat exchangers, two for the hydraulic system and one for the cutting fluid pumping subunit. The activation of the cooling subunit is intermittent and based on the reference value for the output temperature of the cold water;

- Cutting fluid pumping subunit (CFluid): this subunit is responsible for the pumping and further application of cutting fluid during the grinding operation. It consists of a high-flow vacuum pump, a filtering element and an application nozzle;

Table 2

Dressing conditions.

\begin{tabular}{|c|c|c|c|c|c|c|c|c|}
\hline $\begin{array}{l}\text { Wheel } \\
\text { Type }\end{array}$ & $\begin{array}{l}\mathrm{v}_{\mathrm{s}} \\
{[\mathrm{m} / \mathrm{s}]}\end{array}$ & $\begin{array}{l}\text { Depth of } \\
\text { cut }[\mu \mathrm{m}]\end{array}$ & $\begin{array}{l}\text { Traverse rate } \\
{[\mathrm{mm} / \mathrm{min}]}\end{array}$ & $\begin{array}{l}\text { Lead } \\
{[\mathrm{mm} / \mathrm{rot}]}\end{array}$ & $\begin{array}{l}\text { Number of } \\
\text { passes [-] }\end{array}$ & $\begin{array}{l}\text { Disc speed }^{\mathrm{a}} \\
{[\mathrm{m} / \mathrm{s}]}\end{array}$ & $\begin{array}{l}\text { Speed } \\
\text { ratio }^{\mathrm{a}}[-]\end{array}$ & $\begin{array}{l}\text { Overlap } \\
\text { ratio }^{\text {b }}[-]\end{array}$ \\
\hline $\mathrm{cBN}$ & 80 & 2 & 501 & 0.13 & 5 & 32 & 0.4 & - \\
\hline $\mathrm{Al}_{2} \mathrm{O}_{3}$ & 45 & 20 & 451 & 0.25 & 10 & - & - & 4 \\
\hline
\end{tabular}

\footnotetext{
a Disc speed and speed ratio are dressing specifications related to the electric rotary dressing system.
}

b Overlap ratio is a dressing parameter related to the static Fliesen dressing tool. 


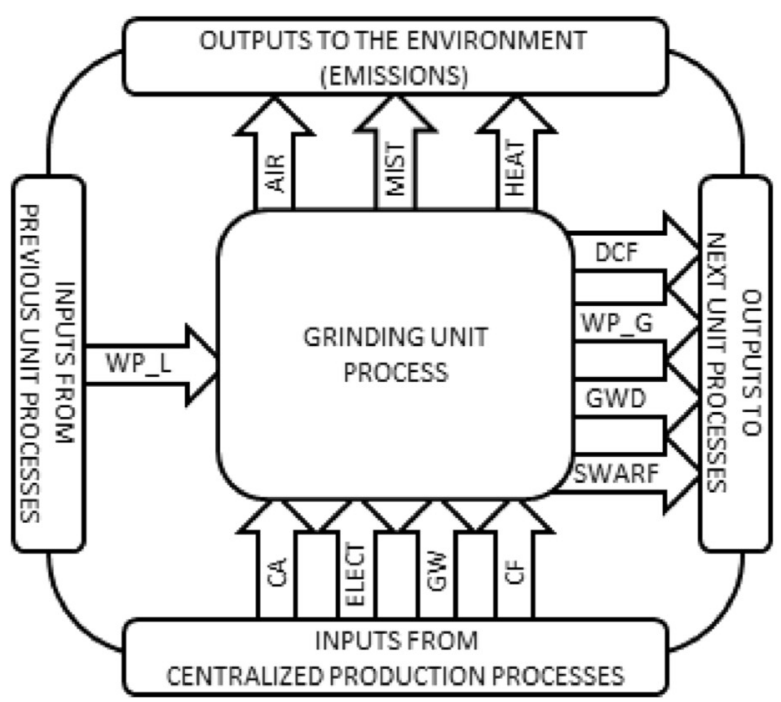

INPUTS FROM PREVIOUS UNIT

PROCESSES

Lathed Workpiece (WP_L)

INPUTS FROM CENTRALIZED

PRODUCTION PROCESSES

Compressed Air (CA)

Electric Energy (ELECT)

Grinding Wheel (GW)

Cutting Fluid (CF)

OUTPUTS TO THE ENVIRONMENT

(EMISSIONS)

Air (AIR)

Mist (MIST)

Heat (HEAT)

OUTPUTS TO THENEXT UNIT

PROCESSES

Dirty Cutting Fluid (DCF)

Ground Workpiece (WP_G)

Grinding Wheel Debris ( $\overline{G W D}$ )

WorkpieceSwarf (SWARF)

Fig. 1. System boundary of the grinding unit process.
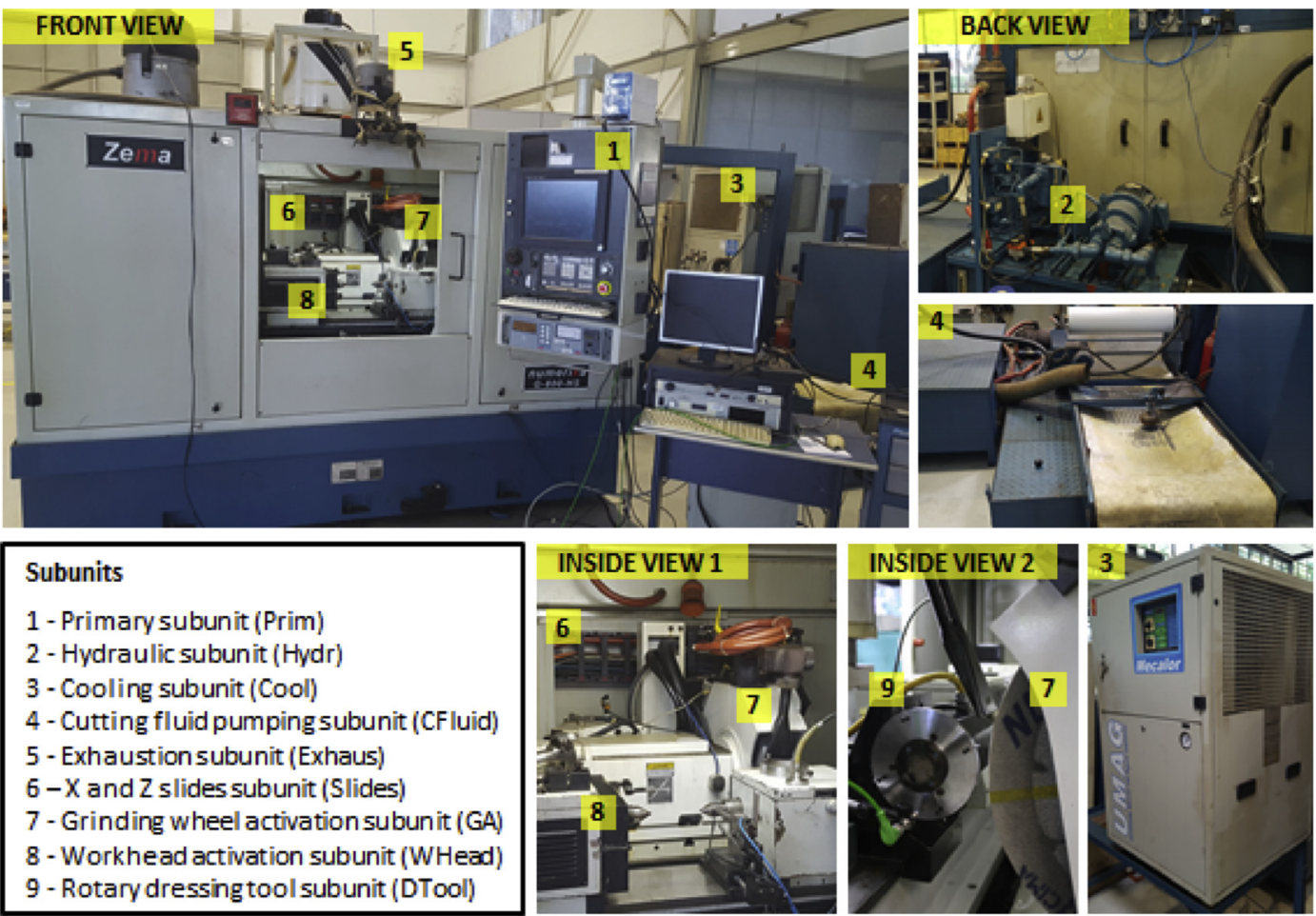

Fig. 2. Zema Numerika G 800-HS grinding machine and its subunits

- Exhaustion subunit (Exhaus): in charge of filtering the mist generated during grinding, it consists of electric motor, fan and filtering elements;

- $X$ and $Z$ slides subunit (Slides): this subunit oversees both $X$ and $\mathrm{Z}$ slides drives and it consists of servomotor, encoder and recirculating ball screws;

- Grinding wheel activation subunit (GA): responsible for the wheelhead activation, it consists of the wheelhead itself, a variable-speed drive and a 37-kW electric motor;

- Workhead activation subunit (WHead): responsible for the workpiece rotational movement and it consists of workhead, servomotor and positioning encoder;
- Rotary dressing tool subunit (DTool): this subunit oversees the electric rotary dressing system used to dress the cBN wheel. It consists of an electric motor and a diamonded disk.

\subsection{Production modes}

The production modes represent the working states of the machine and embrace both machining and non-machining modes (e.g., standby and off modes). After identifying the main grinding subunits and defining the set of experiments, eleven different production modes were characterized, five non-machining modes and six machining modes (Table 3 ): 
Table 3

Relation among the machine production modes and subunits.

\begin{tabular}{|c|c|c|c|c|c|c|c|c|c|}
\hline \multirow[t]{2}{*}{ ProductionMode } & \multicolumn{9}{|c|}{ Subunit } \\
\hline & Prim & Hydr & Cool & CFluid & Exhaus & Slides & GA & WHead & DTool \\
\hline Off & - & - & - & - & - & - & - & - & - \\
\hline Start-up/Shutdown & - & - & - & - & - & - & - & - & - \\
\hline Standby & $\bullet$ & $\bullet$ & $\odot$ & $\bullet$ & 0 & 0 & $\bigcirc$ & 0 & - \\
\hline $\mathrm{Al}_{2} \mathrm{O}_{3}$ dressing wheel & $\bullet$ & 0 & $\odot$ & 0 & 0 & 0 & 0 & 0 & - \\
\hline cBN dressing wheel & $\bullet$ & $\bullet$ & $\odot$ & $\bullet$ & $\bullet$ & $\bullet$ & 0 & 0 & - \\
\hline cBN_Q ${ }^{\prime}{ }_{w} 0.83$ & $\bullet$ & 0 & $\odot$ & 0 & 0 & 0 & 0 & 0 & - \\
\hline cBN_Q ${ }^{\prime}{ }_{w} 1.67$ & $\bullet$ & $\bullet$ & $\odot$ & 0 & $\bullet$ & 0 & 0 & 0 & - \\
\hline cBN_Q ${ }^{\prime}{ }_{w} 2.5$ & $\bullet$ & $\bullet$ & $\odot$ & $\bullet$ & $\bullet$ & $\bullet$ & $\bullet$ & $\bullet$ & - \\
\hline $\mathrm{Al}_{2} \mathrm{O}_{3} \mathrm{Q}^{\prime}{ }_{w} 0.167$ & $\bullet$ & $\bullet$ & $\odot$ & - & $\bullet$ & 0 & 0 & $\bullet$ & - \\
\hline $\mathrm{Al}_{2} \mathrm{O}_{3} \mathrm{Q}^{\prime}{ }_{w} 0.83$ & $\bullet$ & $\bullet$ & $\odot$ & $\bullet$ & $\bullet$ & $\bullet$ & $\bullet$ & $\bullet$ & - \\
\hline $\mathrm{Al}_{2} \mathrm{O}_{3} \mathrm{Q}^{\prime}{ }_{\mathrm{w}} 1.67$ & $\bullet$ & $\bullet$ & $\odot$ & $\bullet$ & $\bullet$ & $\bullet$ & $\bullet$ & $\bullet$ & - \\
\hline
\end{tabular}

Subunit activated.

Subunit energized but not activated.

$\odot$ Subunit energized with intermittent activation;

- Subunit not energized and not activated (off).

- Off: non-machining mode in which the machine is off (and so are all the subunits);

- Start-up/Shutdown: this non-machining mode refers to a situation in which just the primary subunit is activated and all the other ones are off;

- Standby: non-machining mode in which the machine is ready to operate a grinding (machining) or a dressing mode;

- $\mathbf{A l}_{2} \mathbf{O}_{3}$ wheel dressing: this non-machining mode is accessed when a dressing operation with $\mathrm{Al}_{2} \mathrm{O}_{3}$ wheel takes place;

- cBN wheel dressing: this non-machining mode is accessed when a dressing operation with $\mathrm{cBN}$ wheel takes place;

- Machining modes: the six machining modes represent the designed experiments previously shown in Table 1.

\subsection{Unit process life cycle inventory data}

\subsubsection{Consumption of electric energy and compressed air}

The inventory data quantification for both electric energy and compressed air inputs were performed using a web-based acquisition system developed by Filleti et al. (2014), based on the MTConnect machine tools communication protocol (Fig. 3):

- In Loco Measurement: A calibrated solid-state power transducer (Model UPD 600, from Ciber do Brasil) is used to acquire the machine energy consumption. A RS-485/USB converter translates the output data from the power transducer. The compressed air input is acquired by a calibrated turbine-type air flowmeter (model VTG, from Incontrol) installed at the compressed air supply line. The analogic 4-20 mA flowmeter output is converted to a $1-5 \mathrm{~V}$ output by a $250 \Omega$ resistive load and then wired to an analog input card NI9205 connected to a cDAQ-9174 chassis, both from National Instruments. The outputs from both transducer and cDAQ-9174 chassis are received by the Adapter via USB;

- Adapter: It performs the translation of the information provided by the measurement system into flow data and makes them available for the Agent via TCP/IP protocol;

- Agent: This software organizes the acquired data in XML format and makes them available for the Client application. The version used in this study was the MTConnect $\mathrm{C}++$ Agent Version 1.2.0.18;

- Client: This application has been installed at the LAPRAS main server and periodically collects the data provided by the Agent to build the machine tool LCI database.

\subsubsection{Grinding wheel consumption and grinding wheel debris emission}

The quantification of the grinding wheel consumption was performed by the profile analysis from the wheel wear. After each grinding operation, the wheel profile was "printed" on a SAE1010 steel plate, by grinding the plate with a very gentle plunge infeed and abundant cutting fluid flow rate to minimize additional wheel wear. The printed profile was further analyzed by a profilometer (model Form Talysurf 50, from Taylor Hobson). The worn and the preserved grinding regions were measured and compared to estimate the radial reduction by wheel wear and, subsequently, the volumetric wheel wear $\left(\mathrm{V}_{\mathrm{s}}\right)$. This volume was used to quantify both the grinding wheel consumption (GW) and grinding wheel debris emissions (GWD).

From the information provided by Aurich et al. (2013) and Kirsch et al. (2014) studies, it was also possible to estimate the embodied energy on the construction of the two investigated wheels (Table 4).

The embodied energy per abrasive layer for the $\mathrm{cBN}$ wheel was

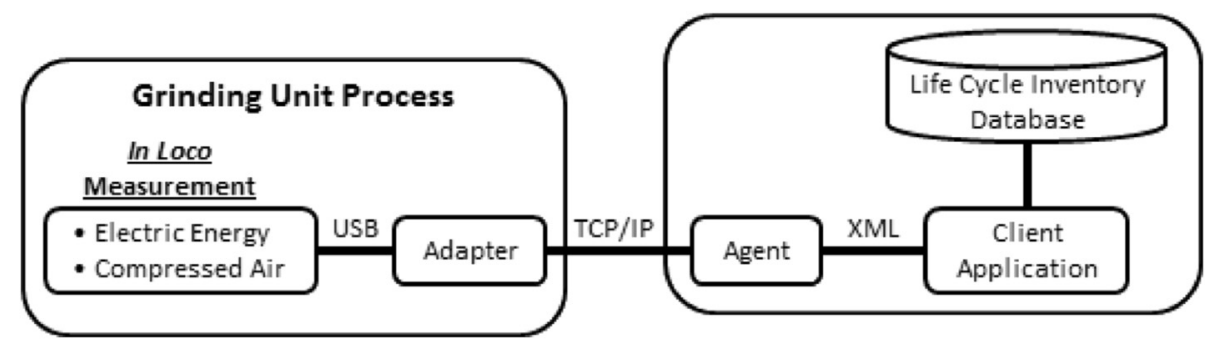

Fig. 3. MTConnect based acquisition system scheme. Adapted from Filleti et al. (2014). 
Table 4

Embodied energy per volume of abrasive layer for the $\mathrm{cBN}$ and $\mathrm{Al}_{2} \mathrm{O}_{3}$ wheels.

\begin{tabular}{|c|c|c|c|c|c|c|c|c|}
\hline \multirow[t]{2}{*}{ Wheel } & \multicolumn{2}{|l|}{ Material } & \multicolumn{5}{|l|}{ Manufacturing } & \multirow{2}{*}{$\begin{array}{l}\text { Total } \\
{\left[\mathrm{J} / \mathrm{mm}^{3}\right]}\end{array}$} \\
\hline & $\begin{array}{l}\text { Grain } \\
{\left[\mathrm{J} / \mathrm{mm}^{3}\right]}\end{array}$ & $\begin{array}{l}\text { Bond } \\
{\left[\mathrm{J} / \mathrm{mm}^{3}\right]}\end{array}$ & $\begin{array}{l}\text { Mixing \& Sieving } \\
{\left[\mathrm{J} / \mathrm{mm}^{3}\right]}\end{array}$ & $\begin{array}{l}\text { Pressing } \\
{\left[\mathrm{J} / \mathrm{mm}^{3}\right]}\end{array}$ & $\begin{array}{l}\text { Drying } \\
{\left[\mathrm{J} / \mathrm{mm}^{3}\right]}\end{array}$ & $\begin{array}{l}\text { Firing } \\
{\left[\mathrm{J} / \mathrm{mm}^{3}\right]}\end{array}$ & $\begin{array}{l}\text { Final Machining } \\
{\left[\mathrm{J} / \mathrm{mm}^{3}\right]}\end{array}$ & \\
\hline $\begin{array}{l}\frac{\mathrm{cBN}^{\mathrm{a}} 400 \times 20 \times 200, \text { vitrified bond, }}{5} \mathrm{~mm} \text { layer thickness, } \\
\text { low carbon steel body }\end{array}$ & 209.52 & 48.35 & 926.72 & & & & & 1184.60 \\
\hline$\underline{\mathrm{Al}}_{2} \frac{\mathrm{O}}{3}^{\mathrm{b}} 500 \times 32 \times 203.2$, & 21.04 & 3.51 & 0.01 & 0.30 & 0.10 & 19.11 & 0.16 & 44.23 \\
\hline
\end{tabular}

a Source: Aurich et al. (2013).

b Source: Kirsch et al. (2014).

Table 5

DCF, mist and CF flows of all machining modes.

\begin{tabular}{|c|c|c|c|}
\hline $\begin{array}{l}\text { Machining } \\
\text { Mode }\end{array}$ & $\begin{array}{l}\text { Dirty cutting } \\
\text { fluid emission } \\
\text { [g] }\end{array}$ & $\begin{array}{l}\text { Mist } \\
\text { emission } \\
{[\mathrm{g}]}\end{array}$ & $\begin{array}{l}\text { Cutting fluid } \\
\text { consumption } \\
\text { [g] }\end{array}$ \\
\hline cBN_Q ${ }^{\prime}{ }_{w} 0.83$ & 68.83 & 3.74 & 72.57 \\
\hline cBN_Q ${ }^{\prime}{ }_{w} 1.67$ & 34.21 & 1.86 & 36.07 \\
\hline cBN_Q ${ }_{w}^{\prime} 2.5$ & 22.85 & 1.24 & 24.09 \\
\hline $\mathrm{Al}_{2} \mathrm{O}_{3} \mathrm{Q}^{\prime}{ }_{\mathrm{w}} 0.167$ & 342.10 & 18.59 & 360.69 \\
\hline $\mathrm{Al}_{2} \mathrm{O}_{3} \mathrm{Q}_{\mathrm{w}}^{\prime} 0.83$ & 68.83 & 3.74 & 72.57 \\
\hline $\mathrm{Al}_{2} \mathrm{O}_{3} \mathrm{Q}_{\mathrm{w}}^{\prime} 1.67$ & 34.21 & 1.86 & 36.07 \\
\hline
\end{tabular}

$1184.60 \mathrm{~J} / \mathrm{mm}^{3}$, while for the $\mathrm{Al}_{2} \mathrm{O}_{3}$ one was much lower, $44.23 \mathrm{~J} /$ $\mathrm{mm}^{3}$ (Table 4). Yet, the higher value of embodied energy from the cBN wheel can be compensated by its resilience against wear, as it will be shown in Section 4.2. In fact, the trade-offs during the selection process between these two grinding wheels can be only verified by a detailed investigation, such as an LCI study.

\subsubsection{Cutting fluid consumption, mist and dirty cutting fluid emissions}

The cutting fluid used was a solution constituted by 10 parts of water and 1 part of synthetic fluid (Archem Química Ltd, 2012), resulting in a mixture of water ( $94.32 \%$ by mass), monoethanolamine primary amine ( $1.20 \%$ by mass), polixetonium chloride algaecide, polyalkylene glycol, dicarboxylic amide and boric amide. The resulting specific mass of the mixture was $1.008 \mathrm{~g} / \mathrm{cm}^{3}$.

The cutting fluid consumption (CF) was calculated as the sum of dirty cutting fluid (DCF) and mist emission flows. Both DCF and mist emission were estimated according to the ratios used by Kalla et al. (2009) for CNC rotating machining tool. For DCF emissions, they assume a ratio of $0.28 \mathrm{~cm}^{3} / \mathrm{s}$, or $0.29 \mathrm{~g} / \mathrm{s}$, as the effective loss of cutting fluid due to degradation. Regarding mist emission, Kalla et al. (2009) assume a ratio of $0.1053 \mathrm{~g} / \mathrm{min}$ of aerosol loss for a cutting fluid application of $5700 \mathrm{~g} / \mathrm{min}$, or $0.0018 \%$ of aerosol loss during fluid application. In the present case, the application of cutting fluid at the grinding zone was adjusted in $50,000 \mathrm{~cm}^{3} / \mathrm{min}$ (see Section 3) for all machining conditions, resulting in a mist loss ratio of $0.92 \mathrm{~cm}^{3} / \mathrm{min}$, or $0.0155 \mathrm{~g} / \mathrm{s}$.

From these ratios, it was possible to calculate the DCF, mist and CF values for all machining modes (Table 5):

\subsubsection{Remaining flows}

For the remaining flows, it was assumed:

- All the compressed air consumed by the unit process was transformed into air emission to the environment, using the
Ideal Gas Law, the specific gas constant for dry air $\mathrm{R}_{\mathrm{d}}=287.06 \mathrm{~J} \mathrm{~K}^{-1} \mathrm{~kg}^{-1}$ (IUPAC, 2009) and the room temperature during the experiments, $295 \mathrm{~K}$ (about $21.9{ }^{\circ} \mathrm{C}$ );

- All machining modes were addressed with the same value for workpiece swarf generation: $3000 \mathrm{~mm}^{3}$, or $24.66 \mathrm{~g}$ (Special Metals, 2008), of Inconel 751;

- The heat flow was included to respect the theoretical energy balance of the unit process. However, according to Kellens et al.(2012a), the heat emission to the environment should be documented just in view of allowing future allocation, for example, as a potential heating source for production halls. This is not the case here, so the heat flow was not accounted for this study.

\subsection{Productive performance analysis}

The productive performance analysis was carried out following two different criteria parameters: G-ratio and arithmetic average roughness $R_{a}$ from the ground workpieces. The $G$-ratio is associated with the grinding wheel lifespan (i.e., wheel wear) and productivity, and is defined as (Equation (1)):

$G=\frac{V_{w}}{V_{s}}$

where:

- $\mathbf{G}=$ G-ratio [-].

- $\mathbf{V}_{\mathbf{w}}=$ Volume of removed material from the workpiece $\left[\mathrm{mm}^{3}\right]$.

- $\mathbf{V}_{\mathbf{s}}=$ Volume of wheel wear $\left[\mathrm{mm}^{3}\right]$.

The $R_{a}$ represents a finishing and quality surface parameter of the ground workpiece and, as defined in Section 3.1., shall be lower than $1 \mu \mathrm{m}$ for all studied machining modes. The roughness measurement was performed using a Taylor Hobson roughness tester, model Surtronic 25, configured with a Gauss filter and cutoff criteria of $0.8 \mathrm{~mm}$. For each grinding step of the workpiece, three measurements were performed, perpendicular to the grinding marks and equally spaced at $120^{\circ}$.

\subsection{Environmental performance analysis}

The environmental performance analysis was carried out in line with the attributional model for LCA studies. The Life Cycle Impact Assessment phase adopted the Environmental Design of Industrial Products 97 (EDIP 97) method for evaluating the life cycle impacts of grinding (Wenzel et al., 1997).

According to the Joint Research Centre - JCR (2010) and Iritani et al. (2015), the EDIP 97 is a midpoint method based on global 
models and indicators, differently from other more updated models such as IMPACT 2002+, EDIP 2003, and ReCiPe 2008, which are more regionalized for European conditions.

Eleven different impact categories were selected for the study: global warming potential (GWP), ozone layer depletion potential (OLD), acidification potential (AP), photochemical oxidation potential (POP), nutrient enrichment potential (NEP), chronic water ecotoxicity potential (EPWC), acute water ecotoxicity potential (EPWA), chronic soil ecotoxicity potential (EPS), human toxicity potential via soil (HTS), human toxicity potential via water (HTW), human toxicity potential via air (HTA).

The environmental performance of the grinding unit process was modeled using the GaBi 6.5 software and the LCI data was obtained by complying to the specifications provided in Section 3.4. In addition, secondary data was also used to complement the system boundary with background LCI data, as described below.

The electric energy consumption used the Brazilian electricity grid mix dataset, provided by PE International (2011), in order to include the impacts of electric energy generation and transmission to the final user. This dataset was also utilized to model the environmental impacts associated with the compressed air production and the embodied energy related to $V_{S}$.

The cutting fluid consumption used the EU tap water dataset (PE International, 2013a) and the monoethanolamine dataset (from $\mathrm{GaBi}$ Extension database XIII: ecoinvent integrated - PE International, 2013b) to include the impacts associated with the tap water supply chain and the surfactant production.

The remaining embodied components from the grinding wheel and the cutting fluid consumptions were not considered in this study due the lack of available datasets.

\section{Results and discussion}

\subsection{Subunits and production modes mapping}

The mapping of the subunits was performed by the activation of one or more subunits at the same time, in order to identify and isolate their requirements of power and compressed air flow. Table 6 presents the average results for each subunit:

With regards to Table 6 , it can be inferred that auxiliary subunits such as the hydraulic, cooling (activated), cutting fluid pumping and the exhaustion demanded higher power requirements than the grinding wheel activation subunit performing free spinning. On the other hand, the $\mathrm{X}$ and $\mathrm{Z}$ slides subunit and the workhead activation subunit showed no significant power requirement when activated.

Fig. 4 illustrates this situation by means of a power profile:

From Table 6 and Fig. 4, it is possible to identify which subunits were the major power demanding, assisting the identification of energy improvement hotspots for the manufacturing process and for the grinding machine itself.

Fig. 4 also present some major instant power spikes. They occur after the activation of exhaustion subunit (at moment $418 \mathrm{~s}$ ) and grinding wheel activation subunit (at moment $452 \mathrm{~s}$ ) and are triggered by the starting current from their respective electric motors. Additionally, between the moment 37 s (activation of hydraulic subunit, cutting fluid pumping subunit and energization of cooling subunit) and moment $117 \mathrm{~s}$ (intermittent activation of cooling subunit), there is a minor power spike followed by a power decrease trend. This behavior is mostly induced by the stabilization of the hydraulic fluid pressure after the activation of hydraulic subunit.

With regard to the compressed air supply, it is required just for the hydraulic and rotary dressing tool subunits activation. During its mapping, the consumption rate from the hydraulic subunit varied from $406 \mathrm{~cm}^{3} / \mathrm{s}$ to $561 \mathrm{~cm}^{3} / \mathrm{s}$, in accordance with its minmax control system. The activation of the rotary dressing tool subunit represented an additional requirement of $106.17 \mathrm{~cm}^{3} / \mathrm{s}$ (Table 6).

The power and the compressed air flow requirements regarding the production modes are shown in Table 7:

Regarding the power requirements, the modes with higher $\mathrm{Q}^{\prime}{ }_{\mathrm{w}}$ have demanded more power to operate, as expected. For an equal value of $\mathrm{Q}^{\prime}{ }_{\mathrm{w}}$ and different grinding wheels, the machining modes using $\mathrm{cBN}$ showed power requirements $24 \%$ to $32 \%$ higher than using the $\mathrm{Al}_{2} \mathrm{O}_{3}$, due the higher cutting speed $\left(\mathrm{v}_{\mathrm{s}}\right)$ used for the $\mathrm{cBN}$ wheel. Similarly, the cBN wheel dressing mode also presented a higher power demand compared to the $\mathrm{Al}_{2} \mathrm{O}_{3}$ one (about $14 \%$ higher). Lastly, due to the extra requirement from the rotary dressing tool subunit, the $\mathrm{cBN}$ wheel dressing mode demanded more compressed air flow than the other modes. Excluding the modes with no compressed air requirements (Start-up/Shutdown and Off modes), the average compressed air demand from the remaining production modes was within the range of the air min-max control system from the hydraulic subunit (from $406 \mathrm{~cm}^{3} / \mathrm{s}$ to $561 \mathrm{~cm}^{3} / \mathrm{s}$ ).

\subsection{Consumption of resources}

After the conclusion of the electric energy and compressed air mapping, it was possible to estimate the consumption of each input flow for all machining modes (Table 8):

From Table $8, \mathrm{Al}_{2} \mathrm{O}_{3}{ }_{2} \mathrm{Q}^{\prime}{ }_{\mathrm{w}} 0.167$ and cBN_Q ${ }^{\prime}{ }_{\mathrm{w}} 2.5$ modes presented the highest and the lowest electric energy consumptions, respectively. These values seem to contradict the results from Table 7, which showed the highest power value for $\mathrm{CBN}_{-} \mathrm{Q}^{\prime}{ }_{\mathrm{w}} 2.5$ and the lowest one for $\mathrm{Al}_{2} \mathrm{O}_{3} \mathrm{Q}^{\prime}{ }_{\mathrm{w}} 0.167$.

The main point for this apparent contradiction is the machining time. Even though the power requirement for cBN_Q ${ }^{\prime}{ }^{2} 2.5$ is $54 \%$ higher than for $\mathrm{Al}_{2} \mathrm{O}_{3}-\mathrm{Q}^{\prime}{ }_{\mathrm{w}} 0.167$, the $\mathrm{Q}^{\prime}{ }_{\mathrm{w}}$ value for the cBN test

Table 6

Average power and compressed air flow requirement from each subunit.

\begin{tabular}{|c|c|c|}
\hline Subunit & Power $[\mathrm{kW}]$ & Compressed Air Flow $\left[\mathrm{cm}^{3} / \mathrm{s}\right]$ \\
\hline Primary subunit (Prim) & 0.54 & - \\
\hline Hydraulic subunit (Hydr) & 4.20 & 479.00 \\
\hline Cooling subunit (Cool) - Energized & 0.48 & - \\
\hline Cooling subunit $(\mathrm{Cool})-$ Activated $^{\mathrm{a}}$ & 3.27 & - \\
\hline Cutting fluid pumping subunit (CFluid) & 4.18 & - \\
\hline $\mathrm{X}$ and $\mathrm{Z}$ slides subunit (Slides) & - & - \\
\hline Exhaustion subunit (Exhaus) & 2.21 & - \\
\hline Workhead activation subunit (WHead) & - & - \\
\hline Grinding wheel activation subunit $(\mathrm{GA})^{\mathrm{b}}$ & 1.50 & - \\
\hline Rotating dressing tool subunit (DTool) & 0.16 & 106.17 \\
\hline
\end{tabular}

a Extra consumption from the cooling subunit caused by its intermittent activation.

b Configuration with the $\mathrm{Al}_{2} \mathrm{O}_{3}$ wheel, $\mathrm{v}_{\mathrm{s}}=45 \mathrm{~m} / \mathrm{s}$ and no machining operation (free spinning). 


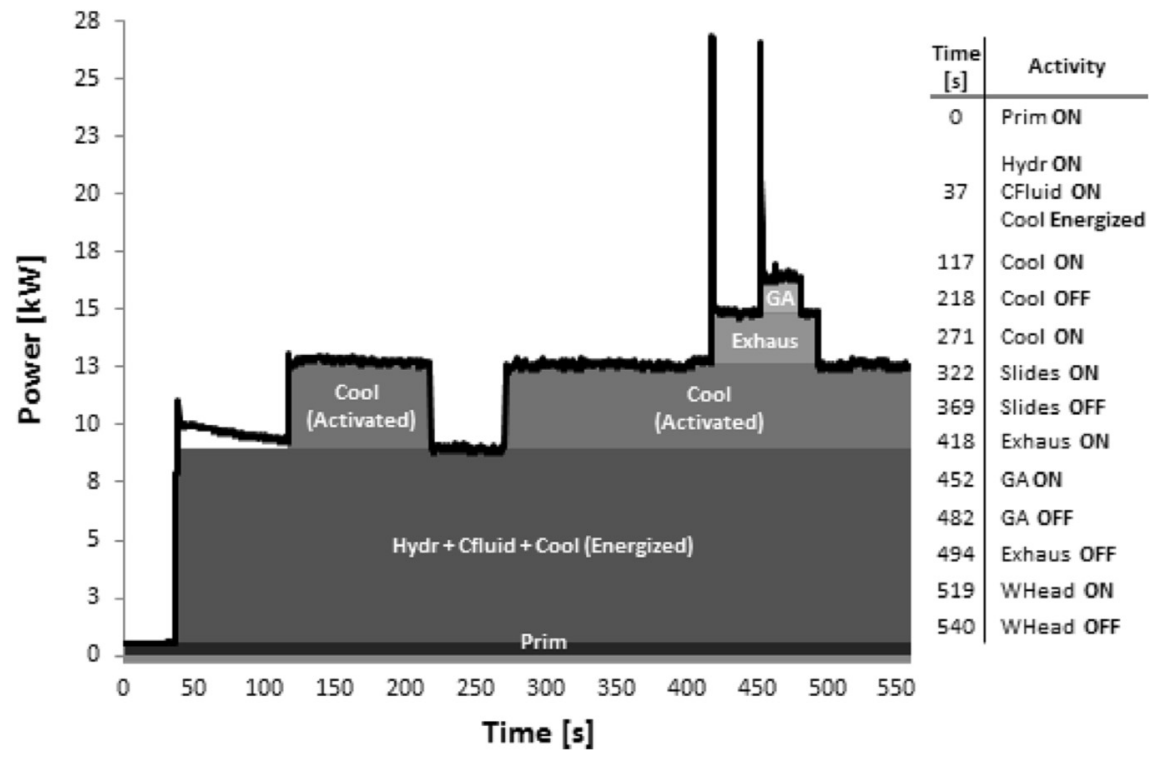

Fig. 4. Power profile for each subunit.

Table 7

Average power and compressed air requirements of each production mode.

\begin{tabular}{lll}
\hline Production mode & Power $[\mathrm{kW}]$ & Compressed Air Flow $\left[\mathrm{cm}^{3} / \mathrm{s}\right]$ \\
\hline Off & 0.00 & 0.00 \\
Start-up/Shutdown & 0.54 & 0.00 \\
Standby & 9.40 & 479.00 \\
$\mathrm{Al}_{2} \mathrm{O}_{3}$ wheel dressing & 16.45 & 422.36 \\
$\mathrm{cBN}$ wheel dressing & 18.79 & 585.18 \\
$\mathrm{cBN} \mathrm{Q}^{\prime}{ }_{\mathrm{w}} 0.83$ & 21.69 & 452.04 \\
$\mathrm{cBN} \mathrm{Q}^{\prime}{ }_{\mathrm{w}} 1.67$ & 22.11 & 453.00 \\
$\mathrm{cBN} \mathrm{Q}^{\prime}{ }_{\mathrm{w}} 2.5$ & 23.23 & 450.33 \\
$\mathrm{Al}_{2} \mathrm{O}_{3} \mathrm{Q}^{\prime}{ }_{w} 0.167$ & 15.07 & 467.30 \\
$\mathrm{Al}_{2} \mathrm{O}_{3} \mathrm{Q}^{\prime}{ }_{\mathrm{w}} 0.83$ & 16.48 & 476.50 \\
$\mathrm{Al}_{2} \mathrm{O}_{3} \mathrm{Q}^{\prime}{ }_{\mathrm{w}} 1.67$ & 17.88 & 493.05 \\
\hline
\end{tabular}

condition is 15 times higher, which means a machining time 15 times lower for the same amount of removed material (i.e., $3000 \mathrm{~mm}^{3}$ ). The effect from this lesser machining time overwhelmingly surpasses the higher power requirement for cBN_Q ${ }^{\prime}{ }_{w} 2.5$ and reduces its electric energy consumption by about 10 times in comparison with the consumption of $\mathrm{Al}_{2} \mathrm{O}_{3} \mathrm{Q}^{\prime}{ }_{\mathrm{w}} 0.167$. For grinding conditions with different wheels and equal values of $\mathrm{Q}^{\prime}{ }_{\mathrm{w}}$ (equal machining times), both electric energy consumption and power requirements were, respectively, 24 and 32\% higher for the $\mathrm{cBN}$ wheel, due to the higher value of $\mathrm{v}_{\mathrm{s}}$.

Machining time also regulated the consumption of compressed air and cutting fluid, as the machining modes with highest $\mathrm{Q}^{\prime}{ }_{\mathrm{w}}$ (lowest machining times) presented the lowest consumptions for compressed air and cutting fluid.
Finally, for each machining mode, the embodied energy from wheel wear was calculated multiplying the embodied energy per volume of abrasive layer (see Table 4 ) by the respective wheel wear volumes (Table 8). It is worth mentioning here that the final embodied energy values represented about $1-3 \%$ of the electric energy consumption and did not substantially affect the environmental performance, as it will be shown in Section 4.4.

\subsection{Productive performance results}

Fig. 5 presents the G-ratio results for the studied grinding modes. Since the volume of removed material from the workpiece $\left(V_{w}\right)$ was $3000 \mathrm{~mm}^{3}$ for all the machining modes, the G-ratio results were only influenced by the volume of wheel wear $\left(V_{s}\right)$ of each mode. For both wheels, a higher value of $\mathrm{Q}^{\prime}{ }_{\mathrm{w}}$ will result in greater wheel wear and lower G-ratio, due to an increased toughness of the grinding operation.

Regarding the different abrasive type, the modes using cBN wheel showed the best $\mathrm{G}$-ratio results, about 35-45 times higher than the ones using $\mathrm{Al}_{2} \mathrm{O}_{3}$ wheel with same $\mathrm{Q}^{\prime}{ }_{\mathrm{w}}$ value. This better performance from cBN was influenced by some key factors. The first factor was structural, the cBN wheel has greater bond and grains hardness if compared with the $\mathrm{Al}_{2} \mathrm{O}_{3}$ one. $\mathrm{cBN}$ higher hardness makes it more suitable for difficult-to-machine nickelbase alloys, such as Inconel 751 (Choudhury and El-Baradie, 1998). Secondly, the higher $\mathrm{v}_{\mathrm{s}}$ used for the $\mathrm{cBN}$ wheel contributed to decrease the forces coming on the grit, which reduces wheel wear (Juneja et al., 2003).

Table 8

Consumption of resources for each machining mode.

\begin{tabular}{|c|c|c|c|c|c|}
\hline Machining Mode & Electric Energy [kJ] & Compressed Air [kg] & Wheel Wear $\left[\mathrm{mm}^{3}\right]$ & Wheel Wear Embodied Energy [kJ] & Cutting Fluid [g] \\
\hline cBN_Q ${ }^{\prime}{ }_{w} 0.83$ & 5682.92 & 0.98 & 32.68 & 38.72 & 72.57 \\
\hline cBN_Q ${ }^{\prime}{ }_{w} 1.67$ & 2904.73 & 0.49 & 36.10 & 42.76 & 36.07 \\
\hline cBN_Q ${ }_{w}^{\prime} 2.5$ & 2037.08 & 0.33 & 41.00 & 48.57 & 24.09 \\
\hline $\mathrm{Al}_{2} \mathrm{O}_{3} \mathrm{Q}^{\prime}{ }_{\mathrm{w}} 0.167$ & $20,039.62$ & 5.13 & 867.30 & 38.36 & 360.69 \\
\hline $\mathrm{Al}_{2} \mathrm{O}_{3} \mathrm{Q}^{\prime}{ }_{\mathrm{w}} 0.83$ & 4274.50 & 1.02 & 1252.23 & 55.39 & 72.57 \\
\hline $\mathrm{Al}_{2} \mathrm{O}_{3} \mathrm{Q}_{\mathrm{w}}^{\prime} 1.67$ & 2333.04 & 0.53 & 1784.81 & 78.94 & 36.07 \\
\hline
\end{tabular}




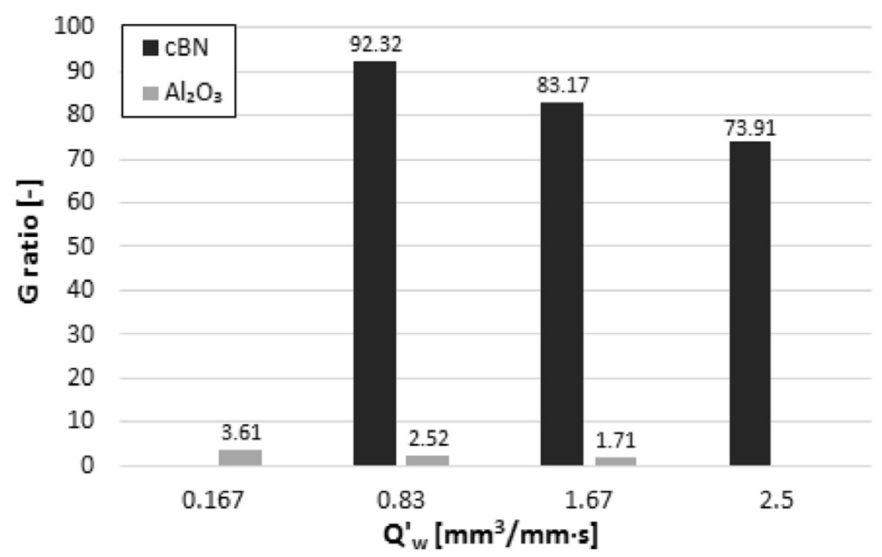

Fig. 5. G-ratio results varying the wheel type and the $Q^{\prime}{ }_{w}$.

The better productive performance of the cBN wheel could be also observed by the average roughness $R_{a}$ results. Fig. 6 details the $R_{\mathrm{a}}$ results for all the tested conditions, measured after $1000 \mathrm{~mm}^{3}$, $2000 \mathrm{~mm}^{3}$ and $3000 \mathrm{~mm}^{3}$ of removed material. cBN wheel presented the best $R_{a}$ results and higher stability over the time. The tested $\mathrm{cBN}$ wheel has an initial advantage over the $\mathrm{Al}_{2} \mathrm{O}_{3}$ one, as it consists of fine grains FEPA-B126, with average size of $142 \mu \mathrm{m}$, which provides better finishing results compared with the $\mathrm{Al}_{2} \mathrm{O}_{3}$ wheel (composed by medium-size US Grit-46 grains, with average size of $508 \mu \mathrm{m}$ ). Still, both wheels were dressed before each grinding operation in order to achieve roughness $R_{a}$ values lower than $1 \mu \mathrm{m}$. For the first $1000 \mathrm{~mm}^{3}$ and $2000 \mathrm{~mm}^{3}$ of material removal, the $R_{a}$ results were below the $1 \mu \mathrm{m}$ threshold for all grinding conditions.

$\mathrm{Al}_{2} \mathrm{O}_{3} \mathrm{Q}^{\prime}{ }_{\mathrm{w}} 0.167$ was the only $\mathrm{Al}_{2} \mathrm{O}_{3}$ mode which obtained $\mathrm{R}_{\mathrm{a}}$ results satisfactorily below the limit of $1 \mu \mathrm{m}$ after removing $3000 \mathrm{~mm}^{3}$ of material. $\mathrm{Al}_{2} \mathrm{O}_{3} \mathrm{Q}^{\prime}{ }_{\mathrm{w}} 1.67$ exceeded this threshold and $\mathrm{Al}_{2} \mathrm{O}_{3} \mathrm{Q}^{\prime}{ }_{\mathrm{w}} 0.83$ was just $2 \%$ below it.

In conclusion, the machining modes using $\mathrm{CBN}$ wheel presented the best results for all productive performance indicators, with $R_{a}$ results much lower than the $1 \mu \mathrm{m}$ threshold and G-ratio results exceeding by substantially more than one order of magnitude the results from the modes using $\mathrm{Al}_{2} \mathrm{O}_{3}$ wheel.

\subsection{Environmental performance results}

Table 9 and Fig. 7 present, respectively, the results of the absolute and the normalized environmental impacts for all machining modes.

Among the selected impact categories, HTA, GWP and HTS showed the higher normalized results. For all machining modes, mist generation represented the totality of HTA impact results, while GWP and HTS results were most affected by electric energy consumption, which accounted from $95.75 \%$ to $98.72 \%$ of GWP results and from $95.37 \%$ to $98.26 \%$ of HTS results (Fig. 8).

Electric energy consumption was also the most impactful flow for the remaining categories: OLD (from 95.70\% to $98.66 \%$ ), AP (from 95.59 to $98.51 \%$ ), POP (from 95.48\% to 98.37\%), NEP (from 95.19\% to $98.02 \%)$, EPWC (82.93\%-86.98\%), EPWA (79.63\%-84.11\%), EPS (from 95.66\% to $98.62 \%$ ) and HTW (93.20\%-96.15\%), depending on the chosen machining mode (Fig. 8).

Dirty cutting fluid emission had a significant participation in EPWC (from 10.62\% to $15.68 \%$ ) and EPWA (from $13.33 \%$ to $19.37 \%$ ) results. The other flows together (i.e., grinding wheel debris emissions and compressed air consumption) contributed little with the impact results, from $0 \%$ to $4.22 \%$ of the total impact, depending on the category and machining mode.

Table 10 summarizes the most important flows for each impact category:

\subsection{Discussion}

Based on the results, it was possible to verify that higher values of $\mathrm{Q}^{\prime}{ }_{\mathrm{w}}$ leads to lower impact results in all environmental impact categories. As previously discussed in Section 4.2, the increase of $\mathrm{Q}^{\prime}{ }_{\mathrm{w}}$ represents the decrease of machining time and, consequently, the decrease of both electric energy and cutting fluid consumption. When both wheels are compared with the same $\mathrm{Q}^{\prime}{ }_{\mathrm{w}}$, there is a slight advantage for the $\mathrm{Al}_{2} \mathrm{O}_{3}$ wheel due to the lower energy requirement to turn the wheel with $45 \mathrm{~m} / \mathrm{s}$ instead of the $80 \mathrm{~m} / \mathrm{s}$ adopted by the cBN wheel.

Electric energy consumption was the most impactful flow for

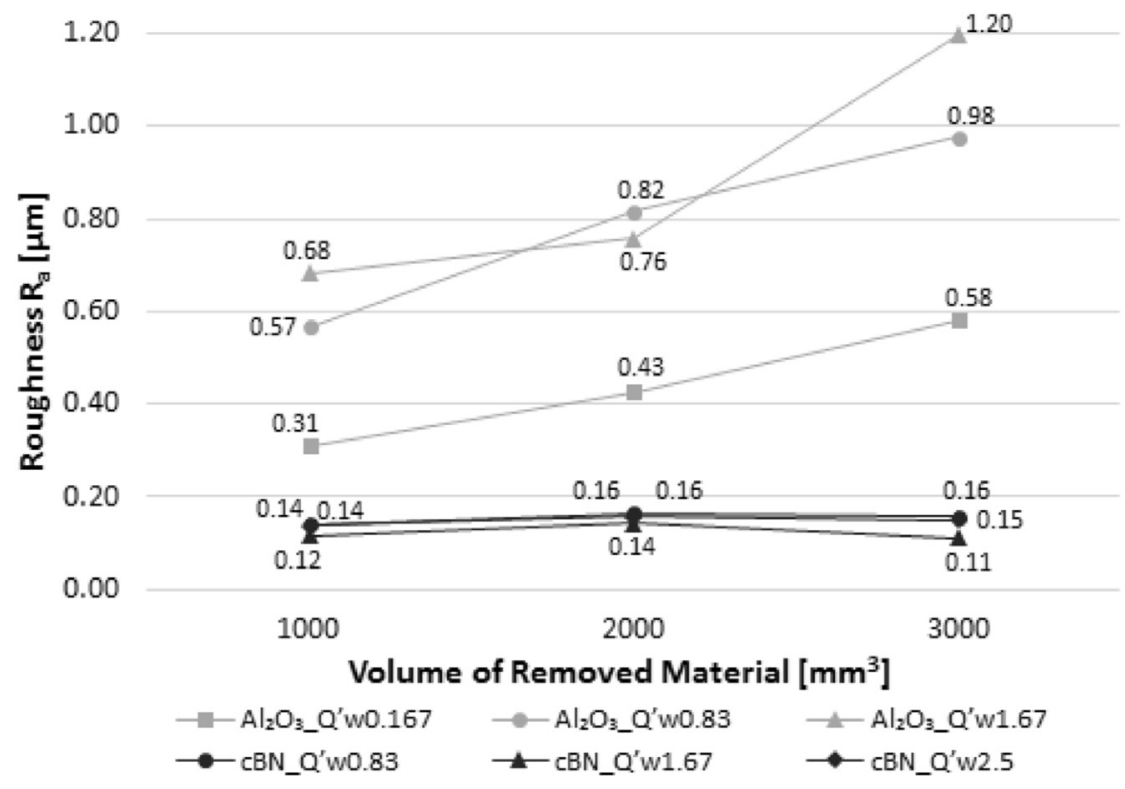

Fig. 6. Roughness $R_{a}$ results for each machining mode. 
Table 9

Environmental impact results from all machining modes, in absolute values.

\begin{tabular}{|c|c|c|c|c|c|c|}
\hline \multirow[t]{3}{*}{ ImpactCategory } & \multicolumn{6}{|c|}{ Machining Mode } \\
\hline & \multicolumn{3}{|l|}{ cBN } & \multicolumn{3}{|l|}{$\mathrm{Al}_{2} \mathrm{O}_{3}$} \\
\hline & $\mathrm{Q}_{\mathrm{w}}^{\prime} 0.83$ & $Q^{\prime}{ }_{w} 1.67$ & $\mathrm{Q}^{\prime}{ }_{\mathrm{w}} 2.5$ & $\mathrm{Q}_{w}^{\prime} 0.167$ & $\mathrm{Q}_{w}^{\prime} 0.83$ & $\mathrm{Q}^{\prime}{ }_{\mathrm{w}} 1.67$ \\
\hline GWP [ $\mathrm{g} \mathrm{CO}_{2}$-Eq.] & 1230 & 634 & 450 & 4315 & 930 & 518 \\
\hline OLD [g R ${ }_{11}$-Eq.] & $2.53 \mathrm{E}-05$ & $1.30 \mathrm{E}-05$ & $9.27 \mathrm{E}-06$ & $8.90 \mathrm{E}-05$ & $1.92 \mathrm{E}-05$ & $1.07 \mathrm{E}-05$ \\
\hline $\mathbf{A P}$ [g SO${ }_{2}$-Eq.] & 2.46 & 1.27 & 0.90 & 8.66 & 1.87 & 1.04 \\
\hline POP [g Ethene-Eq.] & 0.05 & 0.02 & 0.02 & 0.17 & 0.04 & 0.02 \\
\hline NEP [g NO${ }_{3}$-Eq.] & 0.89 & 0.46 & 0.33 & 3.13 & 0.67 & 0.38 \\
\hline EPWC [ m $^{3}$ water] & 3.39 & 1.75 & 1.23 & 12.49 & 2.67 & 1.46 \\
\hline EPWA [ $\mathrm{m}^{3}$ water] & 0.31 & 0.16 & 0.11 & 1.17 & 0.25 & 0.14 \\
\hline EPS $\left[\mathrm{m}^{3}\right.$ soil $]$ & 0.28 & 0.15 & 0.10 & 1.00 & 0.22 & 0.12 \\
\hline HTS $\left[\mathrm{m}^{3}\right.$ soil $]$ & $1.01 \mathrm{E}-02$ & $5.21 \mathrm{E}-03$ & $3.70 \mathrm{E}-03$ & $3.55 \mathrm{E}-02$ & $7.66 \mathrm{E}-03$ & $4.26 \mathrm{E}-03$ \\
\hline HTW $\left[\mathrm{m}^{3}\right.$ water $]$ & 0.21 & 0.11 & 0.08 & 0.75 & 0.16 & 0.09 \\
\hline HTA $\left[\mathrm{m}^{3}\right.$ air $]$ & $1.18 \mathrm{E}+09$ & $5.88 \mathrm{E}+08$ & $3.93 \mathrm{E}+08$ & $5.88 \mathrm{E}+09$ & $1.18 \mathrm{E}+09$ & $5.88 \mathrm{E}+08$ \\
\hline
\end{tabular}

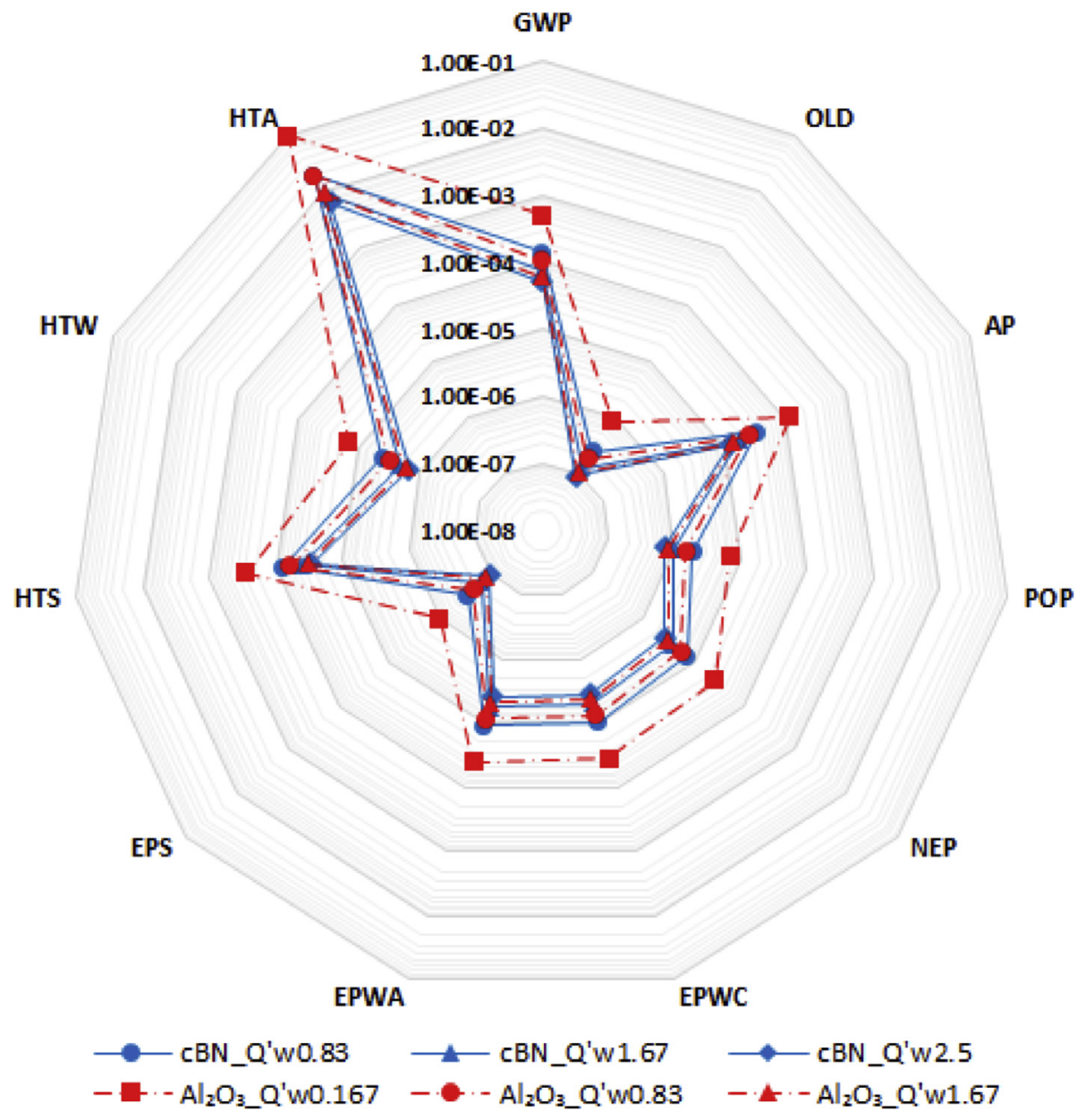

Fig. 7. Environmental impact results normalized per person equivalent (EU 1994).

most of the studied environmental impact categories (Table 10). Efficiency improvements on high power demanding subunits, such as the hydraulic, cutting fluid pumping and exhaustion, may considerably reduce the environmental impacts from grinding. In some cases, they account from $45 \%$ to $70 \%$ of the total electric energy consumption depending on the grinding conditions.

The environmental impacts from electric energy consumption are also tightly related to the energy sources and grid system. Electricity mixes based on high-carbon intensive energy sources (e.g., coal and oil) present very distinct environmental results from the ones based on low-carbon intensive energy sources (e.g., hydropower, nuclear, solar and wind). Thus, the change from the lowcarbon intensive electricity mix used in this study, the Brazilian electricity grid mix dataset (PE International, 2011), to a more carbon-intensive one would represent a great variation in the impact results, especially for GWP, AP, NEP and POP (European Environment Agency, 1998).

Regarding the consumption of cutting fluid, ways of reducing its mist and dirty cutting fluid (DCF) emissions should be pursued to decrease its environmental impacts. In this sense, techniques such 

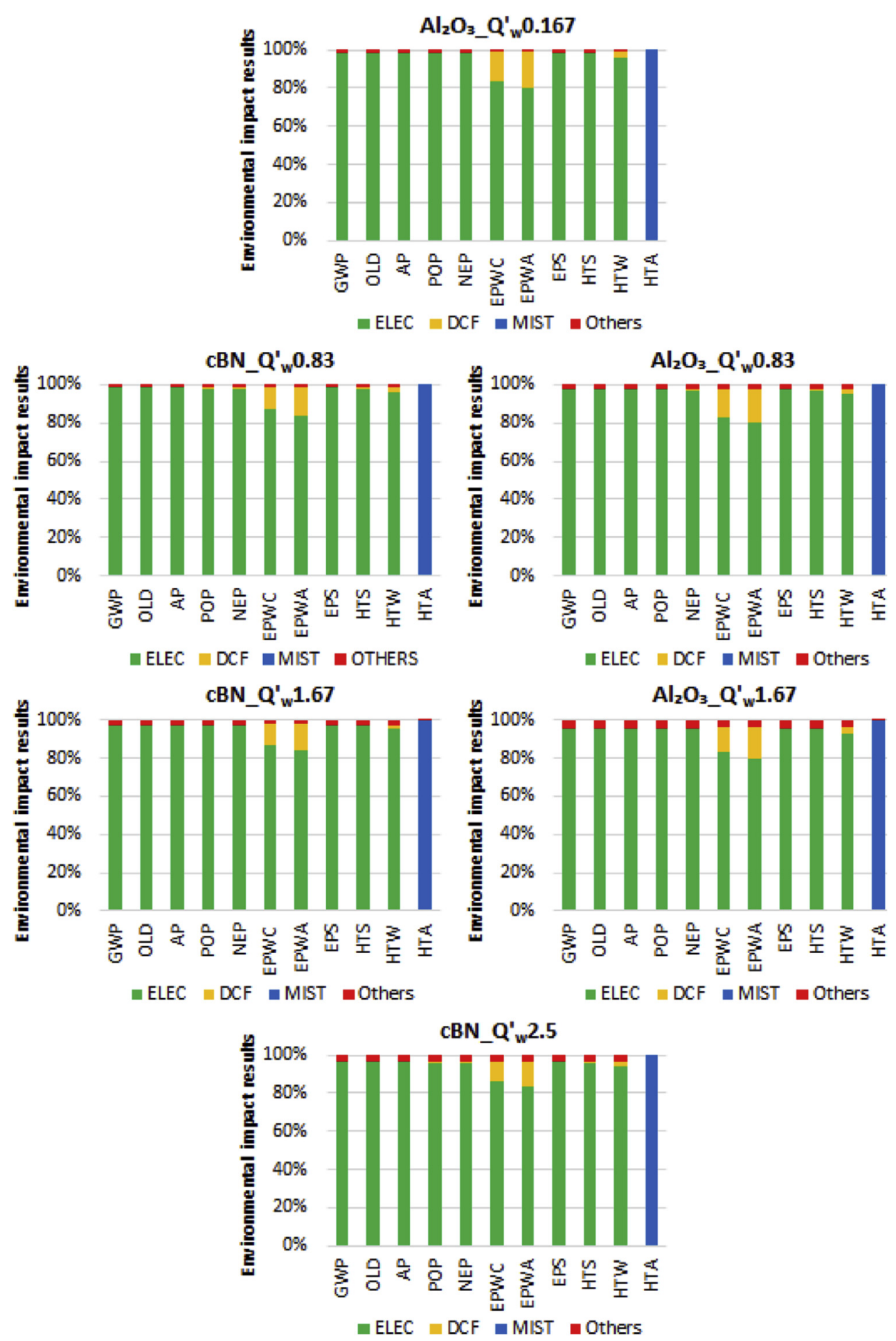

Fig. 8. Potential impacts from each machining mode, separated by relevant flow.

as minimal quantity lubrication (MQL) and dry machining could represent great improvement opportunities (Aurich et al., 2013; Hadad, 2015; Oliveira et al., 2015). Additionally, the use of vegetable-based cutting fluid would also contribute to decrease cutting fluid environmental impacts, as they are produced from renewable sources, possess high biodegradability and are less toxic (Kuram et al., 2013; Lawal et al., 2014; Somashekaraiah et al., 2016).

The present study faced some data limitations, especially the lack of data about cutting fluid components. As an example of how these limitations may interfere the environmental analysis, a lack of LCI data from monoethanolamine (which embodies $1.20 \%$ of the cutting fluid mass) would represent a drastic reduction (over 83.38\%) on all impacts related to the DCF emissions (Fig. 9).

Therefore, the availability and inclusion of the missing LCI data from the other cutting fluid components could represent a significant change on most of the impact categories.

With regard to the productive performance, cBN wheel presented the best results for both $\mathrm{G}$-ratio and $\mathrm{R}_{\mathrm{a}}$ parameters. As 
Table 10

Environmental hotspots for each impact category.

\begin{tabular}{lll}
\hline Impact category & Abbreviation & Most impactful flows (Hotspots) \\
\hline Global warming potential & GWP & Electric energy consumption \\
Ozone layer depletion potential & OLD & Electric energy consumption \\
Acidification potential & AP & Electric energy consumption \\
Photochemical oxidation potential & POP & Electric energy consumption \\
Nutrient enrichment potential & NEP & Electric energy consumption \\
Chronic water ecotoxicity potential & EPWC & Electric energy consumption \& Dirty cutting fluid emission \\
Acute water ecotoxicity potential & EPWA & Electric energy consumption \& Dirty cutting fluid emission \\
Chronic soil ecotoxicity potential & EPS & Electric energy consumption \\
Human toxicity potential via soil & HTS & Electric energy consumption \\
Human toxicity potential via water & HTW & Electric energy consumption \\
Human toxicity potential via air & HTA & Mist emission \\
\hline
\end{tabular}

Dirty Cutting Fluid Emission

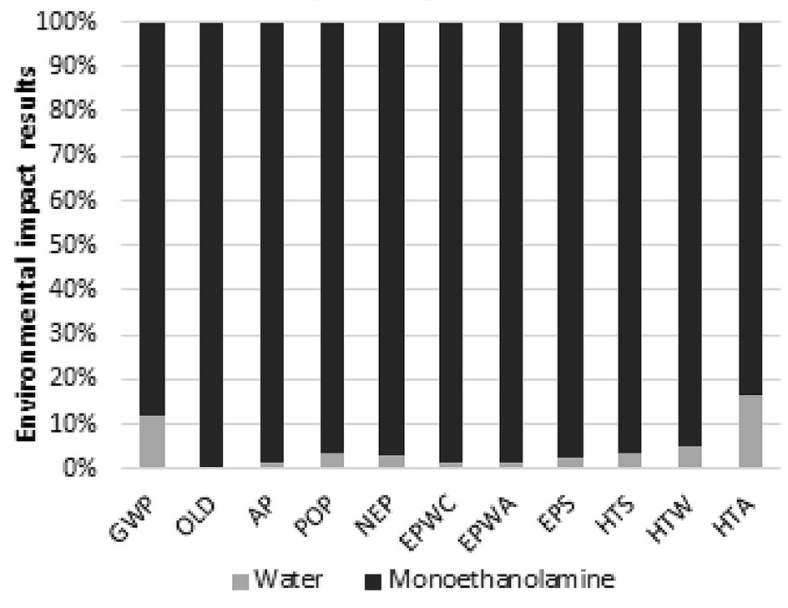

Fig. 9. Potential impacts from DCF emission, separated by component.

previously discussed in Section 4.3, this dominance of cBN wheel is mainly due its structure characteristics. Compared with $\mathrm{Al}_{2} \mathrm{O}_{3}$ wheel, cBN wheel has greater bond and grains hardness, which avoid wheel wear and provide higher G-ratio results. Additionally, cBN wheel consists of finer grains (grain average size $142 \mu \mathrm{m}$ ) compared to $\mathrm{Al}_{2} \mathrm{O}_{3}$ wheel (grain average size $508 \mu \mathrm{m}$ ), which provides better $\mathrm{R}_{\mathrm{a}}$ results.

For both wheels, higher values of $\mathrm{Q}^{\prime}{ }_{\mathrm{w}}$ represented higher wheel wear and, consequently, a lower $\mathrm{G}$-ratios. Increasing $\mathrm{Q}^{\prime}{ }_{\mathrm{w}}$ also affects $\mathrm{R}_{\mathrm{a}}$ results for $\mathrm{Al}_{2} \mathrm{O}_{3}$ wheel, but has no significant effect for $c B N$ wheel.

In conclusion, higher values of $\mathrm{Q}^{\prime}{ }_{\mathrm{w}}$ represented better environmental results and worse G-ratio results for all tested wheels. They also represented worse $\mathrm{R}_{\mathrm{a}}$ results for $\mathrm{Al}_{2} \mathrm{O}_{3}$ wheel. For equal values of $\mathrm{Q}^{\prime}{ }_{\mathrm{w}}, \mathrm{cBN}$ wheel presented better $\mathrm{G}$-ratio and $\mathrm{R}_{\mathrm{a}}$ results and worse environmental results compared with $\mathrm{Al}_{2} \mathrm{O}_{3}$ wheel. However, $\mathrm{Al}_{2} \mathrm{O}_{3} \mathrm{Q}^{\prime}{ }_{\mathrm{w}} 1.67$ and $\mathrm{Al}_{2} \mathrm{O}_{3} \mathrm{Q}^{\prime}{ }_{\mathrm{w}} 0.83$ exceeded or became too close to the $R_{a}=1 \mu \mathrm{m}$ threshold. Thus, the combination of $c B N$ wheel with high values of $\mathrm{Q}^{\prime}{ }_{\mathrm{w}}$ proved to be the best option to improve both the productive and the environmental results.

\section{Conclusions and outlooks}

The present paper contributes with the assessment of grinding sustainability thru a detailed study of the machine subunits and production modes, along with the development of a combined LCA hybrid model and real-time monitoring system to evaluate the consumption of energy, tooling, cutting fluid and compressed air. Besides, a detailed life cycle impact assessment study using eleven different impact categories was performed, in parallel with a productive performance assessment study, to evaluate the variation of wheel type and $Q^{\prime}{ }_{w}$.

The application of the UPLCI methodology played a lead role on the characterization of the grinding unit process and served as a basic framework for this study. MTConnect protocol provided the directives for managing the data from the web-based acquisition system, contributing for the organization and availability of the LCI stratified data from the grinding unit process.

Based on the results, auxiliary subunits such as hydraulic, cooling (activated), cutting fluid pumping and the exhaustion demanded significant power requirements (from $45 \%$ to $70 \%$ ) of the total cradle-to-gate electric energy consumption. Thus, energy efficiency suggestions would enhance considerably the grinding process environmental performance.

For all machining modes, $\mathrm{cBN}$ wheel presented the best productive performance results $-G$-ratio and roughness $R_{a}$ indicators. About the machining modes using $\mathrm{Al}_{2} \mathrm{O}_{3}$ wheel, only $\mathrm{Al}_{2} \mathrm{O}_{3} \mathrm{Q}^{\prime}{ }_{\mathrm{w}} 0.167$ has reasonably matched the productive performance criteria $\mathrm{R}_{\mathrm{a}}<1 \mu \mathrm{m}$. Still, compared with the other machining modes, $\mathrm{Al}_{2} \mathrm{O}_{3} \mathrm{Q}^{\prime}{ }_{\mathrm{w}} 0.167$ had the worst results in all environmental impact categories, due its substantial higher consumption of electric energy and cutting fluid.

Electric energy consumption is the major hotspot for most of the studied environmental impact categories. Hence, the selection of higher values of $\mathrm{Q}^{\prime}{ }_{\mathrm{w}}$ plays an important role in a life cycle perspective. Although the power demand increases with higher values of $\mathrm{Q}^{\prime}{ }_{\mathrm{w}}$, the corresponding reduction in machining time overwhelmingly surpasses the extra power requirement effect, resulting in less overall electric energy consumption.

Cutting fluid consumption is also a relevant environmental hotspot. Aside from the reduced cutting fluid consumption by means of the selection of higher values of $\mathrm{Q}^{\prime}{ }_{\mathrm{w}}$, the use of vegetablebased cutting fluids and techniques such as MQL and dry machining represent promising opportunities to reduce the environmental impacts associated to this flow.

Finally, the selection of high values of $Q^{\prime}{ }_{w}$ with $c B N$ wheel presented the best combination to improve both the productive and the environmental results. Nevertheless, the present work face challenges to gather accurate LCI data for the cutting fluid consumption and the composition of grinding wheel and cutting fluid. The availability of this type of data would considerable enhance the level of detail and precision of the environmental analysis, allowing the achievement of a more accurate analysis in the future.

\section{Acknowledgements}

The authors are grateful for the financial support provided by the National Council for Scientific and Technological Development ("Conselho Nacional de Desenvolvimento Científico e Tecnológico", 
CNPq) [grant number 486251/2011-0]; by the Coordination for Graduate Personnel Improvement ("Coordenação de Aperfeiçoamento de Pessoas de Nível Superior”, CAPES), and by the São Paulo Research Foundation ("Fundação de Amparo à Pesquisa do Estado de São Paulo", FAPESP) [grant number 2013/06736-9].

\section{Appendix A. List of abbreviations}

$\mathrm{Al}_{2} \mathrm{O}_{3} \quad$ Conventional vitrified corundum

$\mathrm{Al}_{2} \mathrm{O}_{3} \mathrm{Q}^{\prime}{ }_{\mathrm{w}} 0.167$ Tested condition using a $\mathrm{Al}_{2} \mathrm{O}_{3}$ wheel and $\mathrm{Q}^{\prime}{ }_{\mathrm{w}}=0.167 \mathrm{~mm}^{3} / \mathrm{mm} \cdot \mathrm{s}$

$\mathrm{Al}_{2} \mathrm{O}_{3} \mathrm{Q}^{\prime}{ }_{\mathrm{w}} 0.83$ Tested condition using a $\mathrm{Al}_{2} \mathrm{O}_{3}$ wheel and $\mathrm{Q}^{\prime}{ }_{\mathrm{w}}=0.83 \mathrm{~mm}^{3} / \mathrm{mm} \cdot \mathrm{s}$

$\mathrm{Al}_{2} \mathrm{O}_{3} \mathrm{Q}^{\prime}{ }_{\mathrm{w}} 1.67$ Tested condition using a $\mathrm{Al}_{2} \mathrm{O}_{3}$ wheel and $\mathrm{Q}^{\prime}{ }_{\mathrm{w}}=1.67 \mathrm{~mm}^{3} / \mathrm{mm} \cdot \mathrm{s}$

AP $\quad\left[\mathrm{kg} \mathrm{SO}_{2}\right.$-Equiv.] Acidification potential

CA $\quad[\mathrm{kg}]$ Compressed air input

CF [g] Cutting fluid input

CFluid Cutting fluid pumping subunit

Cool Cooling subunit

DCF [g] Dirty cutting fluid emission

DTool Rotary dressing tool subunit

EDIP 97 Environmental Design of Industrial Products 97

ELECT [kJ] Electric energy input

EPS $\quad\left[\mathrm{m}^{3}\right.$ soil] Chronic soil ecotoxicity potential

EPWA $\quad\left[\mathrm{m}^{3}\right.$ water] Acute water ecotoxicity potential

EPWC $\left[\mathrm{m}^{3}\right.$ water] Chronic water ecotoxicity potential

Exhaus Exhaustion subunit

G [-] G-ratio

GA Grinding wheel activation subunit

GW $\quad\left[\mathrm{mm}^{3}\right]$ Grinding wheel input

GWD $\left[\mathrm{mm}^{3}\right]$ Grinding wheel debris emission

GWP [kg $\mathrm{CO}_{2}$-Equiv.] Global warming potential

HTA $\quad\left[\mathrm{m}^{3}\right.$ air] Human toxicity potential via air

HTS $\quad\left[\mathrm{m}^{3}\right.$ soil] Human toxicity potential via soil

HTW $\left[\mathrm{m}^{3}\right.$ water] Human toxicity potential via water

Hydr Hydraulic subunit

LCA Life Cycle Assessment

LCI Life Cycle Inventory

MIST [g] Mist emission

NEP [ $\mathrm{kg} \mathrm{NO}_{3}$-Equiv.] Nutrient enrichment potential

OLD [kg R 11 -Equiv.] Ozone layer depletion potential

POP [kg Ethene-Equiv.] Photochemical oxidation potential

Prim Primary subunit

$\mathrm{Q}^{\prime}{ }_{\mathrm{w}} \quad\left[\mathrm{mm}^{3} / \mathrm{mm} \cdot \mathrm{s}\right]$ Specific material removal rate

$\mathrm{R}_{\mathrm{a}} \quad[\mu \mathrm{m}]$ Arithmetic average roughness

$\mathrm{R}_{\mathrm{d}} \quad\left[\mathrm{J} \cdot \mathrm{K}^{-1} \cdot \mathrm{kg}^{-1}\right]$ Specific gas constant for dry air

Slides $\quad \mathrm{X}$ and $\mathrm{Z}$ slides subunit

UPLCI Unit Process Life Cycle Inventory

$V_{\mathrm{w}} \quad\left[\mathrm{mm}^{3}\right]$ Volume of removed material from the workpiece

$V_{\mathrm{s}} \quad\left[\mathrm{mm}^{3}\right]$ Volume of wheel wear

WHead Workhead activation subunit

$\mathrm{b}_{\mathrm{w}} \quad[\mathrm{mm}]$ Grinding width

cBN Cubic boron nitride

${ }^{c B N} Q_{{ }^{\prime}}{ } 0.83$ Tested condition using a cBN wheel and $\mathrm{Q}_{\mathrm{w}}^{\prime}=0.83 \mathrm{~mm}^{3} / \mathrm{mm} \cdot \mathrm{s}$

cBN_Q ${ }^{\prime}{ }_{w} 1.67$ Tested condition using a cBN wheel and $\mathrm{Q}_{\mathrm{w}}^{\prime}=1.67 \mathrm{~mm}^{3} / \mathrm{mm} \cdot \mathrm{s}$

cBN_Q ${ }^{\prime}{ }^{2} 2.5$ Tested condition using a cBN wheel and $\mathrm{Q}^{\prime}{ }_{\mathrm{w}}=2.5 \mathrm{~mm}^{3} / \mathrm{mm} \cdot \mathrm{s}$

$\mathrm{d}_{\mathrm{s}} \quad[\mathrm{mm}]$ Wheel external diameter

$\mathrm{d}_{\mathrm{w}} \quad[\mathrm{mm}]$ Workpiece external diameter

$\mathrm{n}_{\mathrm{w}} \quad[\mathrm{rpm}]$ Workpiece rotation

$\mathrm{v}_{\mathrm{s}} \quad[\mathrm{m} / \mathrm{s}]$ Cutting speed

\section{Appendix A. Supplementary data}

Supplementary data related to this article can be found at http:// dx.doi.org/10.1016/j.jclepro.2017.05.158.

\section{References}

The product life cycle. In: Abele, E., Anderl, R., Birkhofer, H. (Eds.), 2005. Environmentally-Friendly Product Development: Methods and Tools. Springer-Verlag London Limited, pp. 35-126.

Archem Química Ltd, 2012. Security Information Sheet of Chemical Product Product: METCUT SC-101K. Technical Report M.101K, ver. 00-08/12.

Aurich, J.C., Linke, B., Hauschild, M., Carrella, M., Kirsch, B., 2013. Sustainability of abrasive processes. CIRP Ann. - Manuf. Technol. 62, 653-672. http://dx.doi.org/ 10.1016/j.cirp.2013.05.010.

Bourhis, F.L., Kerbrat, O., Hascoet, J.-Y., Mognol, P., 2013. Sustainable manufacturing: evaluation and modeling of environmental impacts in additive manufacturing. Int. J. Adv. Manuf. Technol. 69, 1927-1939. http://dx.doi.org/10.1007/s00170013-5151-2.

Choudhury, I., El-Baradie, M., 1998. Machinability of nickel-base super alloys: a general review. J. Mater. Process. Technol. 77, 278-284. http://dx.doi.org/ 10.1016/S0924-0136(97)00429-9.

Clarens, A.F., Zimmerman, J.B., Keoleian, G.A., Hayes, K.F., Skerlos, S.J., 2008. Comparison of life cycle emissions and energy consumption for environmentally adapted metalworking fluid systems. Environ. Sci. Technol. 42, 8534-8540. http://dx.doi.org/10.1021/es800791z.

Diniz, A., Marcondes, F., Coppini, N., 2013. Processo de Retificação. In: Tecnologia Da Usinagem Dos Materiais. Artliber, São Paulo, pp. 241-269.

European Environment Agency, 1998. Identification of environmental performance indicators to be used for comparison of cleaner technologies. In: Comparing Environmental Impact Data on Cleaner Technologies (CEIDOCT). European Environment Agency (EEA), Copenhagen, pp. 27-72.

Filleti, R.A.P., Silva, D.A.L., Silva, E.J., Ometto, A.R., 2014. Dynamic system for life cycle inventory and impact assessment of manufacturing processes. Procedia CIRP 15 531-536. http://dx.doi.org/10.1016/j.procir.2014.06.024.

Gutowski, T., Dahmus, J., Thiriez, A., 2006. Electrical energy requirements for manufacturing processes. In: 13th CIRP International Conference on Life Cycle Engineering. Leuven, pp. 623-628.

Hadad, M., 2015. An experimental investigation of the effects of machining parameters on environmentally friendly grinding process. J. Clean. Prod. 108, 217-231. http://dx.doi.org/10.1016/j.jclepro.2015.05.092.

Iritani, D.R., Silva, D.A.L., Saavedra, Y.M.B., Grael, P.F.F., Ometto, A.R., 2015. Sustainable strategies analysis through life cycle assessment: a case study in a furniture industry. J. Clean. Prod. 96, 308-318. http://dx.doi.org/10.1016/j.jclepro.2014 05.029.

ISO, 2006a. 14040: Environmental Management - Life Cycle Assessment - Principles and Framework. Geneva.

ISO, 2006b. 14044: Environmental Management - Life Cycle Assessment - Requirements and Guidelines. Geneva.

IUPAC, 2009. IUPAC Compendium of Chemical Terminology. IUPAC, Research Triagle Park, NC. http://dx.doi.org/10.1351/goldbook.

Joint Research Centre - JRC, 2010. International Reference Life Cycle Data System (ILCD) Handbook: Analysing of Existing Environmental Impact Assessment Methodologies for Use in Life Cycle Assessment, first ed. European Union, Ispra.

Juneja, B.L., Sekhon, G.S., Seth, N., 2003. Effect of grinding parameters on grinding wheel performance. In: Fundamentals of Metal Cutting and Machine Tools. New Age International, New Delhi, pp. 254-259.

Kalla, D., Twomey, J., Overcash, M., 2009. MR4 Turning Process: Unit Process Life Cycle Inventory. Wichita.

Kellens, K., Dewulf, W., Overcash, M., Hauschild, M.Z., Duflou, J.R., 2012a. Methodology for systematic analysis and improvement of manufacturing unit process life-cycle inventory (UPLCI)-CO2PE! initiative (cooperative effort on process emissions in manufacturing). Part 1: methodology description. Int. J. Life Cycle Assess. 17, 69-78. http://dx.doi.org/10.1007/s11367-011-0340-4.

Kellens, K., Dewulf, W., Overcash, M., Hauschild, M.Z., Duflou, J.R., 2012b. Methodology for systematic analysis and improvement of manufacturing unit process life cycle inventory (UPLCI) CO2PE! initiative (cooperative effort on process emissions in manufacturing). Part 2: case studies. Int. J. Life Cycle Assess. 17, 242-251. http://dx.doi.org/10.1007/s11367-011-0352-0.

Kirsch, B., Effgen, C., Büchel, M., Aurich, J.C., 2014. Comparison of the embodied energy of a grinding wheel and an end mill. Procedia CIRP 15, 74-79. http:// dx.doi.org/10.1016/j.procir.2014.06.037.

Kuram, E., Ozcelik, B., Bayramoglu, M., Demirbas, E., Simsek, B.T., 2013. Optimization of cutting fluids and cutting parameters during end milling by using D-optimal design of experiments. J. Clean. Prod. 42, 159-166. http://dx.doi.org/10.1016/ j.jclepro.2012.11.003.

Lawal, S.A., Choudhury, I.A., Nukman, Y., 2014. Evaluation of vegetable and mineral oil-in-water emulsion cutting fluids in turning AISI 4340 steel with coated carbide tools. J. Clean. Prod. 66, 610-618. http://dx.doi.org/10.1016/ j.jclepro.2013.11.066.

Li, W., Winter, M., Kara, S., Herrmann, C., 2012. Eco-efficiency of manufacturing processes: a grinding case. CIRP Ann. - Manuf. Technol. 61, 59-62. http:// dx.doi.org/10.1016/j.cirp.2012.03.029. 
Linke, B., Overcash, M., 2012. Life cycle analysis of grinding. In: Dornfeld, D.A., Linke, B.S. (Eds.), Leveraging Technology for a Sustainable World. Springer Berlin Heidelberg, Berlin, Heidelberg, pp. 293-298. http://dx.doi.org/10.1007/ 978-3-642-29069-5_50.

Malkin, S., Guo, C., 2008. Grinding Technology: Theory and Application of Machining with Abrasive. Industrial Press New York, New York.

Special Metals, 2008. Product specification: Inconel alloy 751. http://www specialmetals.com/documents/Inconel alloy 751.pdf (Accessed 27.03.2017).

Oliveira, J.F.G., Silva, E.J., Coelho, R.T., Brozek, L., Bottene, A.C., Marcos, G.P., 2015. Dry grinding process with workpiece precooling. CIRP Ann. - Manuf. Technol. 64 329-332. http://dx.doi.org/10.1016/j.cirp.2015.04.098.

PE International, 2011. Process dataset: BR: electricity grid mix; AC, technology mix; consumption mix, to consumer; <1 kV. In: http://gabi-documentation-2014. gabi-software.com/xml-data/processes/ceb36eee-1612-4101-81a8Ofb8aeac9032.xml (Accessed 10.10.2016).

PE International, 2013a. Process dataset: eu-27: tap water; water purification treatment; production mix, at plant; from surface water. In: http://gabidocumentation-2014.gabi-software.com/xml-data/processes/db009014-338f11dd-bd11-0800200c9a66.xml (Accessed 10.10.2016).

PE International, 2013b. Extension database xiii: ecoinvent integrated - process dataset: rer: monoethanolamine, at plant. http://www.gabi-software.com/ support/gabi/gabi-6-lci-documentation/extension-database-xiii-ecoinvent-integrated/ (Accessed 10.10.2016).

Shao, G., Kibira, D., Brodsky, A., Egge, N., 2011. Decision support for sustainable manufacturing using decision guidance query language. Int. J. Sustain. Eng. 4 251-265. http://dx.doi.org/10.1080/19397038.2011.574741.

Silva, D.A.L., da Silva, E.J., Ometto, A.R., 2016. Green manufacturing: uma análise da produção científica e de tendências para o futuro. Production 26, 642-655. http://dx.doi.org/10.1590/0103-6513.032513.

Silva, D.A.L., Filleti, R.A.P., Christoforo, A.L., Silva, E.J., Ometto, A.R., 2015. Application of life cycle assessment (LCA) and design of experiments (DOE) to the monitoring and control of a grinding process. Procedia CIRP 29, 508-513. http:// dx.doi.org/10.1016/j.procir.2015.01.037.

Skone, T.J., Curran, M.A., 2005. LCAccess - global directory of LCI resources. J. Clean. Prod. 13, 1345-1350. http://dx.doi.org/10.1016/j.jclepro.2005.05.016.

Somashekaraiah, R., S, S.P., Gnanadhas, D.P., Kailas, S.V., Chakravortty, D., 2016. Ecofriendly, non-toxic cutting fluid for sustainable manufacturing and machining processes. Tribol. Online 11, 556-567. http://dx.doi.org/10.2474/trol.11.556.

Thorn, M.J., Kraus, J.L., Parker, D.R., 2011. Life-cycle assessment as a sustainability management tool: strengths, weaknesses, and other considerations. Environ. Qual. Manag. 20,1-10. http://dx.doi.org/10.1002/tqem.20285.

Torrisi, N.M., Oliveira, J.F.G., 2012. Remote monitoring for high-speed CNC processes over public IP networks using CyberOPC. Int. J. Adv. Manuf. Technol. 60, 191-200. http://dx.doi.org/10.1007/s00170-011-3580-3.

Chetan Ghosh, S., Venkateswara Rao, P., 2015. Application of sustainable techniques in metal cutting for enhanced machinability: a review. J. Clean. Prod. 100, 17-34. http://dx.doi.org/10.1016/j.jclepro.2015.03.039.

Vijayaraghavan, A., Sobel, W., Fox, A., Dornfeld, D., Warndorf, P., 2008. Improving machine tool interoperability using standardized interface protocols: MTConnectTM. In: International Symposium on Flexible Automation, p. 6. www. alvarestech.com/temp/capp/nist2010/eScholarship\%20UC\%20item\% 204zs976kx.pdf (Accessed 27.03.2017).

Vijayaraghavan, A., Yuan, C., Diaz, N., Fleschutz, T., Helu, M., 2013. Closed-loop production systems. In: Dornfeld, D. (Ed.), Green Manufacturing. Springer US, Boston, MA, pp. 117-152. http://dx.doi.org/10.1007/978-1-4419-6016-0_6.

Wenzel, H., Hauschild, M., Alting, L., 1997. Environmental Assessment of Products. Volume 1-Methodology, Tools and Case Studies in Product Development, first ed. Kluwer Academic Publishers, Norwell.

Winter, M., Li, W., Kara, S., Herrmann, C., 2014. Determining optimal process parameters to increase the eco-efficiency of grinding processes. J. Clean. Prod. 66, 644-654. http://dx.doi.org/10.1016/j.jclepro.2013.10.031.

Winter, M., Ibbotson, S., Kara, S., Herrmann, C., 2015. Life cycle assessment of cubic boron nitride grinding wheels. J. Clean. Prod. 107, 707-721. http://dx.doi.org/ 10.1016/j.jclepro.2015.05.088. 